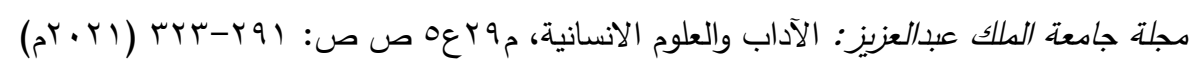

DOI:10.4197/Art.29-5.10

\title{
حجم الاسهام النسبي للمرونة المعرفية في أساليب اتخاذ القرار لدى طلبة الدراسات العليا بجامعة ام القرى
}

\author{
د. - دميرة محارب العتيبي

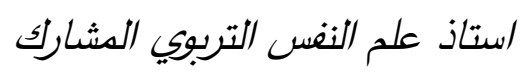 \\ بقسم علم النفس - جامعة ام القرى
}

مستخلص. يهدف البحث الحالي إلى تحديد أكثر أساليب اتخاذ القرار وأكثر ابعاد المرونة استخداماً لدى طلبة

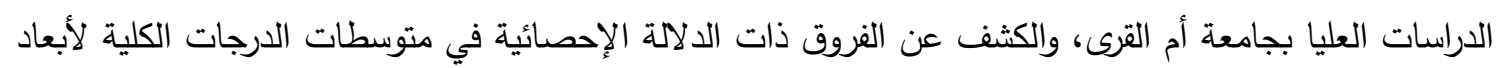

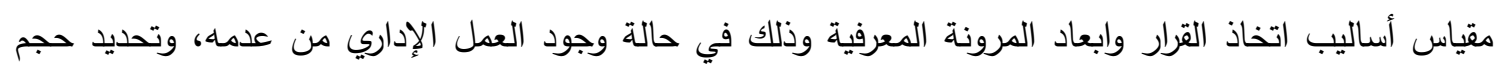

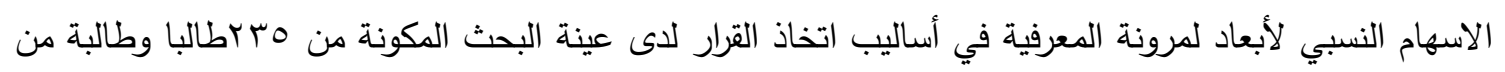

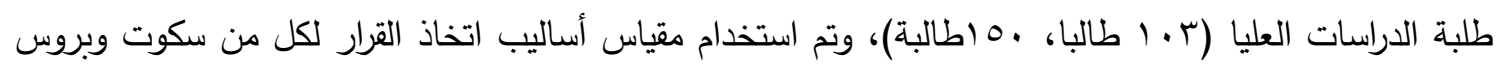
Dennis \& Vander wel Scott \& Bruce

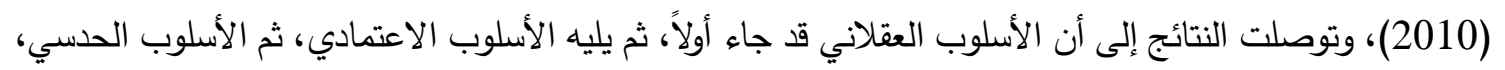

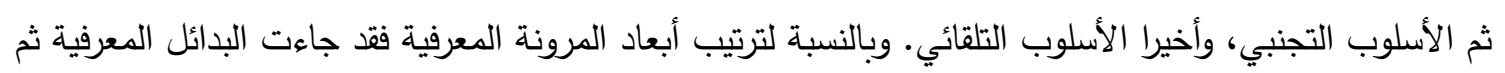

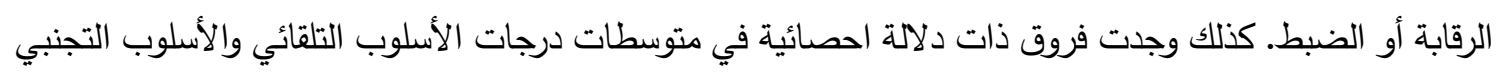

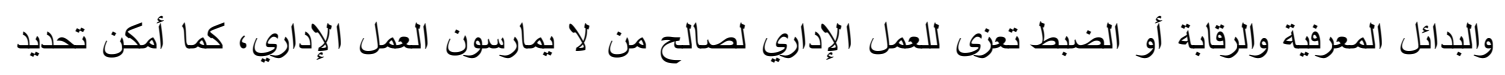

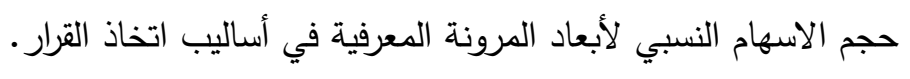

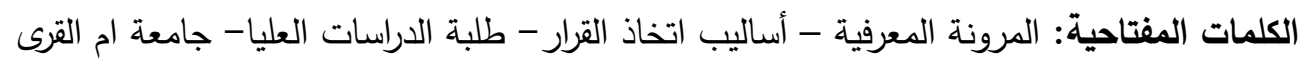

حاجة ماسة ومستمرة لإنجاز قرار أو أكثر، خصوصا فيما يتعلق بتحقيق أهداف الفرد. مما يجعل عملية اتخاذ القرار من أوجه النشاط لفاط

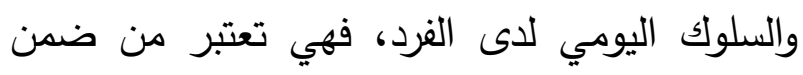

\section{المقدمة}

تعتبر عملية اتخاذ القرار مهمة في حياتنا، فهي عملية نعيشها كل لحظة من لحظات حياتتا ففي المنزل والعمل وفي محيط الحياة الاجتماعية الأخرى هناك لكئك 
مرحله اتخاذ القرار فليست إلا جزء من عملية صنع القرار وآخر خطواته (الخرابشة، ب . . ب).

وقد نشأت وتطورت دراسة اتخاذ القرار وأساليب القرار خلال القرن الماضي، وفي أواخر الأربعينات وأوائل الخمسينات من القرن الماضي، فمعظم البحوث التي تتاولت اتخاذ القرار قد أجريت في مجال علم

النفس تحت مواضيع المعرفة والقيادة ( 1983 Rowe \& Boulgarides, الأطر النظرية والنماذج التي تتاولت عملية صنع القرار أو اتخاذه مثل النموذج العقلاني The Rational Model القرار الرشيد أو العقلاني دون النظر إلى أيه عوامل أخرى قد تتاخل في هذه القدرة ، وتنسب هذه النظرية

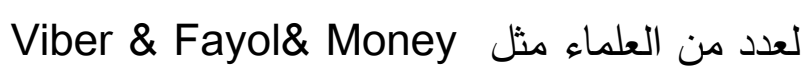
Max v \& Relly \&Gulik \& Tylor والزغلول، r... ) )، ويتحدد القرار العقلاني وفقا لأربعه معايير وهي : الذكاء: في إيجاد مناسبات لاتخاذ قرار ما، والتصميم ويتمثل في اختراع وتطوير وتحليل طرق العمل الممكنة، واختيار مسار عمل معين من تلك المتاحة، ومراجعة تقييم الخيارات السابق، . وفي هذا النوع من العقلانية الكلاسيكية أو المثالية، يتم استخدام طرق تحليل القرار لمعرفة القيم أو المنافع لكل من البدائل خلال مرحلة "الاختيار"، وبذلك تفترض معرفة جميع البدائل الممكنة، ومعرفة عواقب تتفيذ كل بديل، ولديها مجموعة منظمة بشكل جيد من التفضيلات لهذه العواقب، كما لديها القدرة
إستراتيجيات التفكير التي تضم حل المشكلات وتكوين المفاهيم بالإضافة إلى عملية اتخاذ القرار ، ويتعاملون مع كلٍ منها بصورة مستقلة، لأنها تتضمَّن خطوات وعمليات متمايزة عن بعضها البعض، بينما يرى آخرون أن عملية اتخاذ القرار متطابقة مع عملية حل المشكلات، باعتبار أن المشكلات في حقيقة الأمر ليست سوى مواقفت تتطلَّب قرارات حول حلول لهذه المشكلات (جروان، ا ( . ب، 0 . 1).

وتمثل القدرة على اتخاذ القرار جوهر السلوك الذكي، وقد عُرف منذ القدم عن طريق الفلاسفة والرياضيين والاقتصاديين والإحصائيين وبالرغم من ذلك في حين لم يكن لله تاريخ طويل بعلم النفس، فقد ظهرت أول مراجعه واسعة لنظرية اتخاذ القرار بمجله

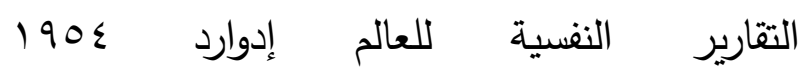
.(Salovic, 1990) وقد أجمع علماء الإدارة وعلم النفس على أن معنى اتخاذ القرار ينطوي على وجود عدد من البدائل التي تتطلب المفاضلة بينها واختيار انسبها، وعلية فإن عملية المفاضلة تعد جوهر عملية اتخاذ القرار وبدونها تتتفي العملية ولا يكون هناك اتخاذ قرار (توفيق

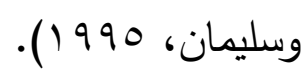

وهناك خلط لدى بعض الباحثين بين مفهوم صنع القرارات واتخاذها، فعملية صنع القرار هي مجموعه من الخطوات والإجراءات المتتابعة تبدأ بتحديد المشكلة وتتتهي باتخاذ القرار وتتفيذه، أما 
وقد ارتبط مصطلح أساليب اتخاذ القرار كثيرا بمصطلح الأساليب المعرفية حيث تتعكس الفروق بين الأفراد بالأساليب المعرفية على أساليبهح في اتخاذ قراراتهم (Anderson, 2000). كما اشتركت الأبحاث حول اتخاذ القرار في افتراض أنه على غرار الأسلوب المعرفي، فإن أسلوب

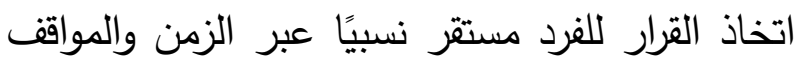
(Pachur, Geisler \& Allwood,2017; كما Davids et. Al., 2016; Spaar,2015) ترتبط أنماط أو أساليب القرار ارتباطًا وثيقًا بالأسلوب

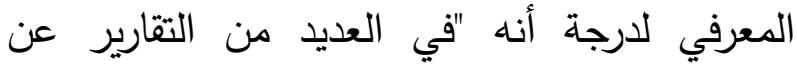
الاختلافات الفردية في صنع القرار، غالبًا ما يستخدم

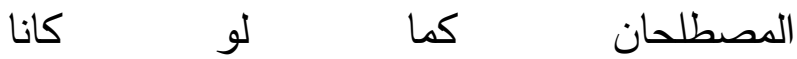
مرادفين(Thunholm,2004,932). وفي ذات السياق ارتبط أسلوب اتخاذ القرار بما

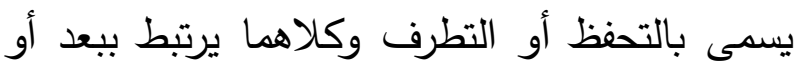

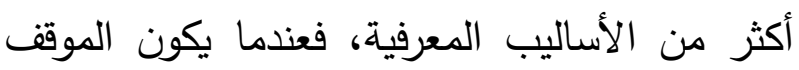
معقدا فقد يميل الفرد إلى مواجهه هذا الموقف بالتحفظ وقد يجازف بقرار اندفاعي لا يلاءم الموقف وذلك بـاك

أيضا وفقا لأسلوبه المعرفي (الفرماوي، ـ9 99 ()). وقد وجد بعض المنظرين بعلم النفس أنه من الصعب دعم فكرة الأساليب المعرفية فيما يتعلق باتخاذ بطن

القرار، وقام ميتيكين وجرين Mytykyn and 1985 Green وخلصا إلى أن مثل هذه النظرية الأسلوبية فيما يتعلق باتخاذ القرار كانت غامضة ومتناقضة. وقد عمل الفل
الحسابية لمقارنة النتائج وتحديد أي منها الأفضل. The model of ويعتبر نموذج العقلانية المقيدة bounded rationality فهي تستتد لعمل سيمون 19V9 Simon إلا أنها تعترف بإن متخذ القرار ليس لديه دائما المعلومات الكافية، وربما تكون الخيارات المثلى ليست مطلوبة دائماً، وتتميز العقلانية المقيدة بأنشطة البحث والرضا، حيث يتم البحث عن البدائل وتقييمها بالتسلسل، فإذا

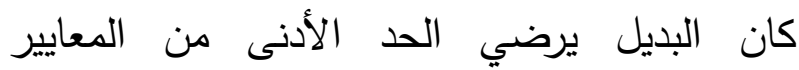
المنصوص عليها صراحة يتم إنهاء عملية البحث. The بالنسبة لنموذج وجهة النظر المتزايدة incrementalist view من الإجراءات التزايدية(خطوة بخطوة)، بحيث تبقي الإستراتيجية مفتوحة للتعديل ويتم إجراء تغييرات هامشية وقابلة للتنفيذ من خلال الوضع الراهن لحل

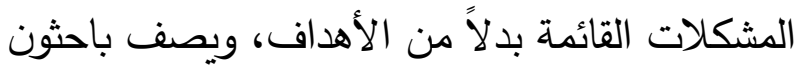

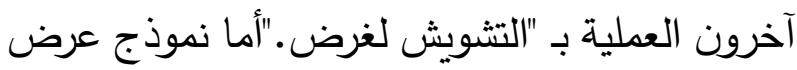
الإجراءات التنظيمية The organisational procedures view التنظيمية إلى فهم القرارات على أنها ناتج إجراءات التشغيل القياسية التي تستدعيها الوحدات الفرعية

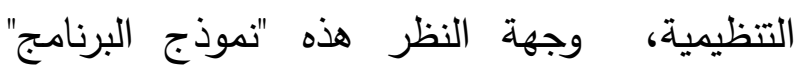

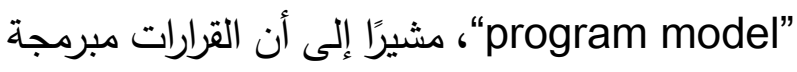
مسبقًا في الإجراءات الحالية بالإضافة إلى التفكير (Turpin \& الروتيني للأشخاص الإجنين .Marais, 2004,144-146) 
(Jacoby , الضباط العسكريين والمهندسين 2007

وتهدف قائمه أساليب اتخاذ القرار تهاف إلى

وصف طريقة الفرد في اتخاذ قراراته وذلك عن طريق تحديد الطرق التي بواسطتها جمع المعلومات وتتظيمها

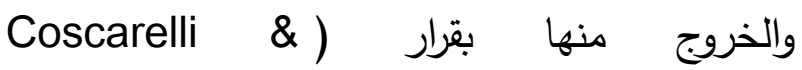
.(Johnson, 2007

كما وضع فريدمان نموذجا ( 2005 , (Furnham والذي يتكون من أربعه أساليب لاتخاذ

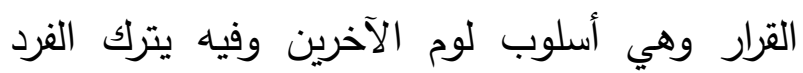

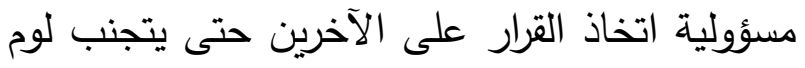

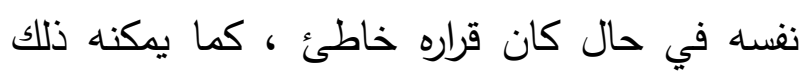

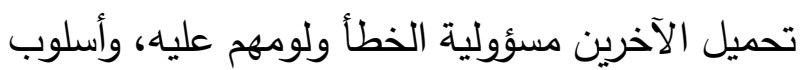
تأجيل اتخاذ القرار والذي يعتبر من أكثر الأساليب

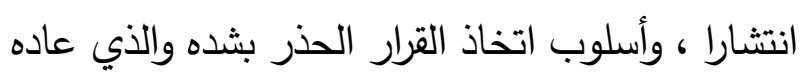
ما يعاني أصحابه من متلازمة الأمعاء المتهيجة

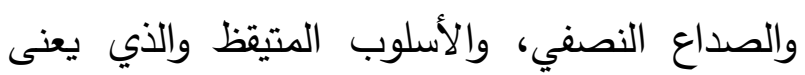

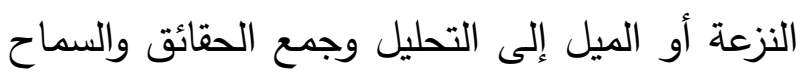
بقدر قليل جدا من الغموض ويواجه عاده أصحاب هذا الأسلوب مشاكل من الثك وعدم اليقين .

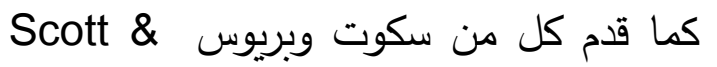
نموذج أساليب اتخاذ القرار (Bruce , 1995) المكون من أربعه أساليب وأضافا أسلوبا خامسا أثناء العمل على المقياس الذي صمماه لقياس هذه الأساليب المبل

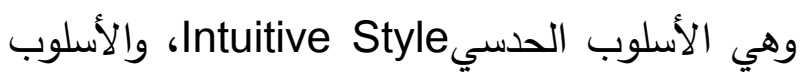
العقلاني Rational Style، والأسلوب التلقائي
بعض المنظرين في مطلع التسعينات على تعريف معنى أسلوب اتخاذ القرار، وقد برزت إلى السطح بعض الاختلافات حول معنى أسلوب اتخاذ القرار .(Jacoby, 2007, 7-8) (1993)Driver, وقد وصف درايفر واخرون et.al بالأسلوب عند اتخاذ القرار وسط الأفراد : العامل الأول

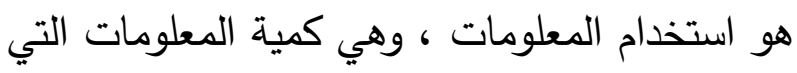
تؤخذ في الاعتبار عند اتخاذ القرار : والعامل الآخر هو المركز، أي عدد الحلول التي تتوفر للمرء قبل

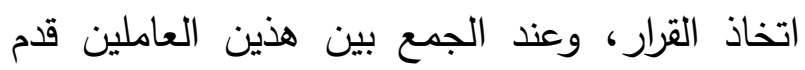
درايفر وزملأوه نموذجا لتقسيم أساليب القرار إلى فئات أو خمسة أساليب أساسية للقرار لاستخدام المعلومات، والأساليب الخمسة التي تم تقديمها كانت: قاطعة، مرنة، تكاملية، هرمية ونظامية. ويمتلك كل من هذه

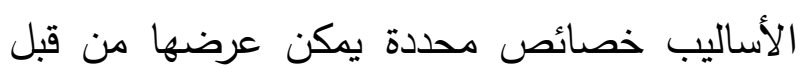
متخذ القرار. وفي هذا الوقت أعاد درايفر صياغة تعريفه حول أسلوب اتخاذ القرار لإدخال المعلومات التي تم تجميعها وعدد البدائل المختارة كعادة مدروسة. وقد أوجد كل من أوجد سكوت وبروس B Bruce والذي يدعمه بحثهم الكلي حول إطارات اتخاذ القرار

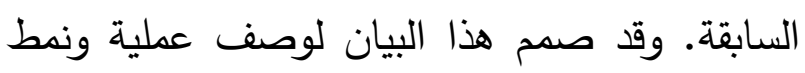
اتخاذ القرار لاى الفرد والمجتمع المستهدف بهذا البيان

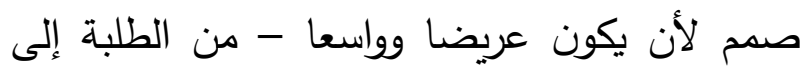


الخبرة والسلوكيات المستفادة، ومع ذلك ، في مواجهة المشكلات غير المنظمة ، مع وجود خيارات غير معروفة ، من المرجح أن يستفيدوا من التفكير والتحليل والتداول. حتى يجد متخذو القرار أن ردودهم المعتادة قد لا تعمل، فإن إمكاناتهم في التغيير محدودة جدًا إذا (Betsch, لم يعملوا على ضبط معالجتهم المعرفية Haberstroh, Glöckner, Haar, \& Fiedler, 2001; Grégoire, Barr \& Shepherd,2010) المعرفية في التغلب على الجمود المعرفي الحادث من خلال السماح لمتخذي القرار بتعديل وضع المعالجة الخاص بهم إلى مواقف مختلفة.

وتعمل المرونة المعرفية كوظيفة معرفية أدائية

تساعد الفرد على تتويع وتغيير أساليب وطرق التعامل

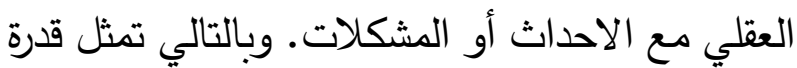
الفرد على التحول المعرفي للتكيف مع المثيرات البيئية (Dennis \& Vandr wal, المتغيرة من حوله ع عله .2010)

ويرى كل من جارج وكافاريتا وفورر (2012) Furr, Cavarretta \& Garg المعرفية يمثل الخصائص والعمليات التي تسمح

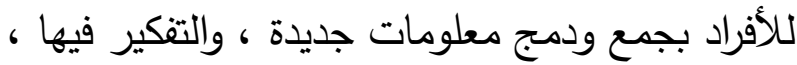
وتعديل وجهات نظرهم تبعا لذلك. كما عرفها اندرسون (2002,83 Aأنها قدرة الفرد على التكيف مع موقف ما يتطلب حل مشكلة ما، وقدرته على الانتقال بسهولة
Spontaneous Style Dependent Style .Avoidant Style

وقد عملت نماذج أسلوب اتخاذ القرار على تصنيف العملية المعرفية للفرد وذلك بتكامل قدراته بفهم المعلومات وتنظيمها والتفكير فيها ومعالجتها وتثكيلها، وأحد التعريفات المستخدمة في مجال أساليب القرار هو تحديد نوع مميز من الثخصية أو السلوك، كما يمكن تعريف أسلوب اتخاذ القرار كنمط عادي أو طريقة مفضلة لأداء شيء يتكون بمرور

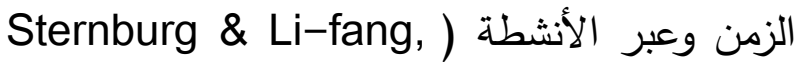
. $(2001$ كذلك فإن عملية اتخاذ القرار ليست مرتبطة ببيئة العمل فقط، ولكنها عملية يمارسها الفرد بشكل طبيعي في حياته اليومية، سواء كانت هذه القرارات اليومية مهمة أو غير ذات أهمية، كما أنها تتعلق بطريقة تفاعله مع احداث البيئة حوله، مما يجعل الافراد بحاجة تحديث تمثيلاتهم العقلية استجابة للتغيرات في البيئة الخارجية \&adkarni ) (Narayanan, 2007) ولتحديث تمشيلاتهم العقلية يجب على متخذي القرار الاستراتيجيين الانخراط أولاً

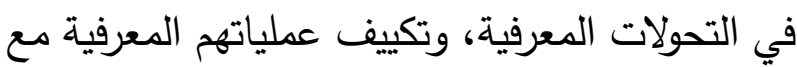
(Foldy, Goldman, \& Ospina, الموقف المحدد) (2008، فإذا كان الموقف ينطوي على مشكلات منظمة بشكل جيد ، مع بدائل معروفة ، يمكن لمتخذي القرار الاستفادة من التفاعل بسرعة ، بالاعتماد على 
وهناك العديد من العوامل التي تعتمد عليها

المرونة المعرفية، وهي تظهر عندما يقوم الفرد بمهمة معقدة، ويجب أن يتكيف سلوكه مع الظروف البيئية التي يتم فيها تتفيذ المهمة. ولكن عندما تستمر هذه لهن الظروف في التغير مع تطور المهمة، يجب على الفرد تركيز الانتباه على هذه الظروف على أساس منتظم. بالإضافة إلى ذلك، من أجل تكييف سلوكه مع لـاه

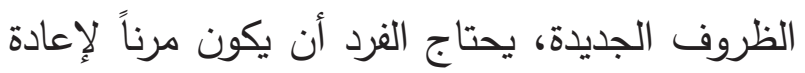

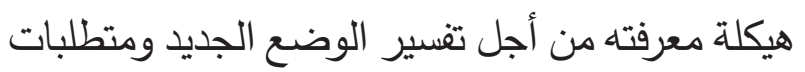

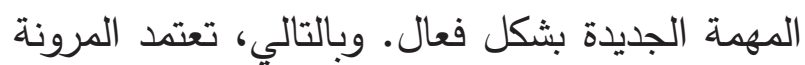
المعرفية على كل من العمليات المطلوبة وتمثيل

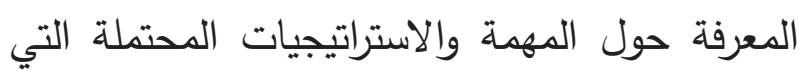

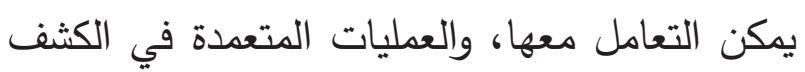
عن تغير الوضع وضرورة الاستجابة غير الروتينية، حيث هناك حاجة إلى مستوى أعلى من التحكم

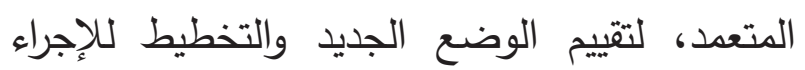
المطلوب اتخاذه، وهذا يعني، أنه من خلال المرونة

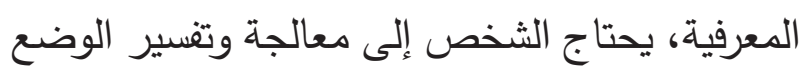

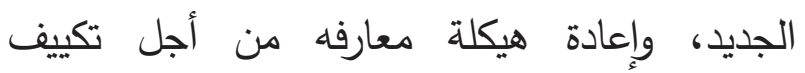

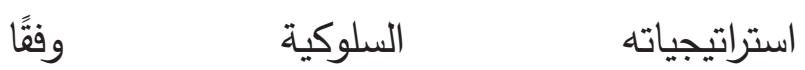
لذلك(Cañas,2006).كذلك تتأثر المرونة المعرفية

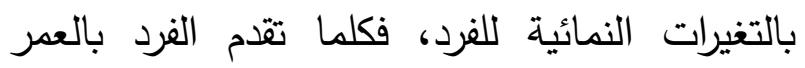
وأصبح أكثر نضجاً، زادت لديه المرونة المعرفية .(Driscoll, 2000)

ويرتبط مفهوم المرونة المعرفية وخاصة عدم المرونة المعرفية المناظرة، بأربعة مفاهيم أخرى تمت لمعتية
ويسر من فكرة إلى فكرة أخري، والنظر إلى تلك المشكلة من خلال وجهات نظر متعددة. ويري جوندوز Gunduz (2013,1049) منان المرونة المعرفية تمثل القدرة على التعامل مع الاحداث الجديدة والمواقف الصعبة، وكذلك القدرة على إنتاج

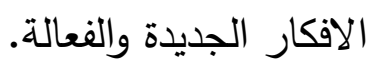
كما يرى كانسس (Cañas, 2006,296) أن المرونة المعرفية هي القدرة الانسانية على تكييف

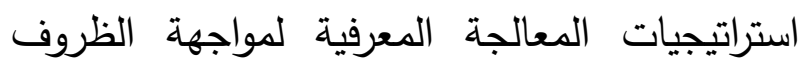
الجديدة وغير المتوقعة في البيئة، ويتضمن هذا التعريف ثلاث خصائص مفاهيمية مهمة. أولاً، المرونة المعرفية هي قدرة يمكن أن تنطوي على عملية تعلم، أي أنها يمكن اكتسابها من خلال الخبرة. ثانيًا، تتضمن المرونة المعرفية تكييف استراتيجيات المعالجة المعرفية. لذلك، تشير المرونة المعرفية إلى التغيرات في السلوكيات المعقدة، وليس في استجابات منفصلة. واخيرا، يتم حدوث التكيف مع التغيرات البيئية الجديدة

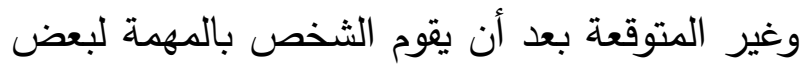

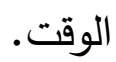
حيث تكمن قوة المرونة المعرفية في جعل الفرد قادر على التعامل مع المواقف المختلفة بطرق مختلفة، خاصة في الاستجابة بفعالية خصوصا مع الأوضاع العاعل

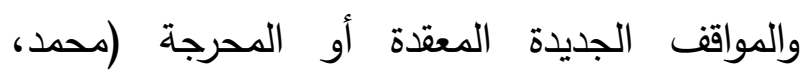
TY (Y)، كما أنها تساعد على زيادة قدرة الأفراد واستعدادهم لتجريب استراتيجيات مختلفة عند تحقيق أي هدف محدد (بلبل وحجازي، 17 • ب). 
المرونة المعرفية بعد ذلك مع الكفاءة الذاتية، الاعتقاد بأن المرء قادر على الأداء، بطريقة معينة، لتحقيق

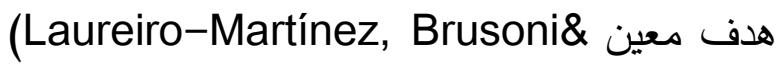

.Zollo, 2009)

وكنلك نموذج دينس وفاندرول Dennis \&Vander wal للمرونة المعرفية هما بعد التحكم أو الضبط ويمثل قدرة الفرد على إدراك المواقف الصعبة والتحكم بها، وبعد البدائل ويمثل قدرة الفرد على تقديم التفسيرات والحلول البديلة والمتعددة لهذه المواقف.

وقد تتاولت الدراسات العلاقة ما بين اتخاذ القرار

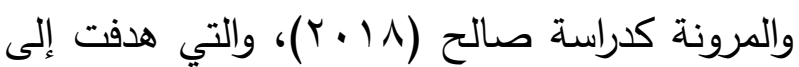
معرفة العلاقة بين اتخاذ القرار والمرونة، وقد بلغت العينة 70 رئيس قسم أكاديمي بالجامعات الفلسطينية، وقد توصلت النتائج لوجود علاقة ذات دلالة إحصائية بين اتخاذ القرار والمرونة النفسية، ولم توجد فروق ذات دلالة إحصائية في القدرة على اتخاذ القرار بين الجنسين، بينما وجدت فروق دالة احصائيا في المرونة

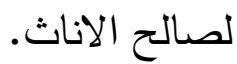

كما تم تناول المتغيرين بالطرق التجريبية كما

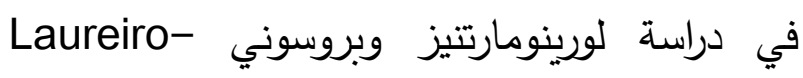
Martínez \& Brusoni معرفة كيف يمكن لصناع القرار الاستراتيجيين التغلب على الجمود عند التعامل مع التغيير، وبلغت العينة 9 §من كبار المديرين التنفيذيين في الثركات متعددة الجنسيات الشركات، ومؤسسو الثركات الصغيرة،
دراستها في سيكولوجية التفكير وهي الحصار المعرفي cognitive blockade في مسار العمل الأول، حتى في المواقف التي يكون التي فيها من المنطقي التغيير إلى مسار عمل بديل، التباطؤ المعرفي من cognitive hysteresis، وهو 1 الميل إلى الالتزام بقرار بعد أن أثبتت الأدلة أنه خطأ.

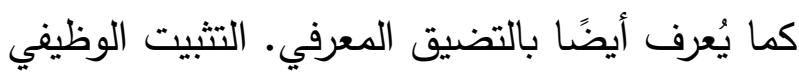
functional fixation المتاحة فقط في المهمة كما هي معروفة من حيث وظيفتها الأكثر شيوعًا، حيث يواجه الأفراد صعوبات في استخدام العناصر التي اتخذت شكلًا جديدًا.

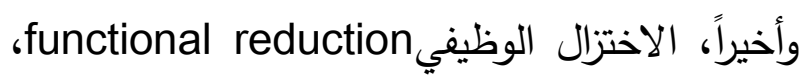
وهو الميل لمواجهة مشكلة تتعلق بسبب واحد مع المع

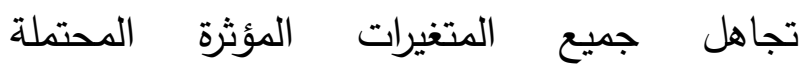
الأخرى(Cañas,2006,297-298). وهناك العديد من النماذج التي تتاولت المرونة Martin \& Rubin المعرفي منها نموذج مارتن وروب لنوبن 990 ام الذي حدد ثلاث مكونات رئيسية. أولاً، يحتاج

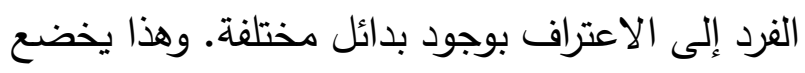
لعملية الإدراك الاجتماعي التي تمكن من الوعي بالبدائل. ثانيًا، بعد الاعتراف بالبدائل المختلفة، يجب اليب

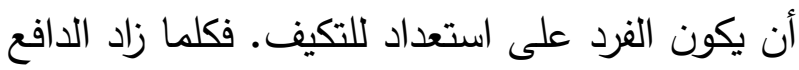
للتكيف، كلما كان الفرد أكثر مرونة. ثالثًا، يحتاج الثخص إلى الثعور بالثقة حيال قدرته على التصرف

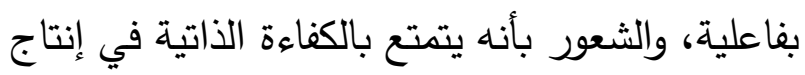

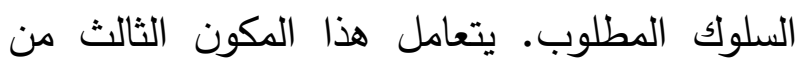


الددارس الثانوية، وتوصلت النتائج إلى وجود علاقات ذات دلالة إحصائية بين المرونة المعرفية واستراتيجيات المواجهة النشطة واستراتيجيات المواجهة السلبية. كما لا توجد علاقة ذات دلالة إحصائية بين المرونة المعرفية واستراتيجيات التجنب.

مثكلة الدراسة وتساؤلاتها:

تعتبر عملية اتخاذ القرار، عملية مستمرة قائمة في العادة على التفاعل بطريقة معينة في سياق قرار معين، تحدد من خلاله أسلوب استجابة المتعلم المعتاد Scott (الذي يظهره الفرد عند مواجهته لحالة قرار مابنها (\&Bruce,1995,p.820)، وبالتالي تشير أساليب اتخاذ القرار إلى أساليب أو أنماط منتهجة شبيهة بالسمات الثابتة في المواقف التي تتطلب اتخاذ قرار بال (Leykin \& DeRubeis, 2010,506) المرونة المعرفية كقدرة مهمة لأنه إذا أراد متخذي

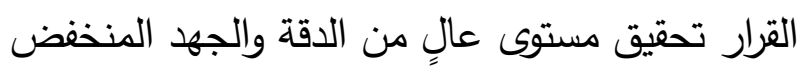
على حدٍ سواء، فسيضطر إلى استخدام مجموعة من الاستراتيجيات، حيث يتوقف الاختيار على متطلبات (Payne, Bettman \& الموقف" Johnson, 1988,539)

وبالتالي يمكن تعريف أو تحديد المرونة المعرفية على أنها القدرة على مطابقة نوع المعالجة

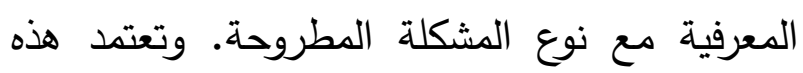
المطابقة على شرطين، أولاهما أن متخذي القرار

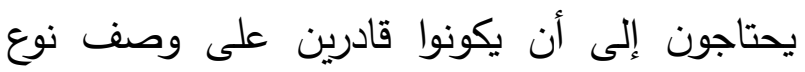
المشكلة التي يواجهونها، وثانيهما يحتاج صانعو القرار
ومديري الوحدات في المؤسسات المتوسطة الحجم، وقد توصلت النتائج إلى أن المرونة المعرفية لها تأثير إيجابي على الأداء ، ويظهر هذا التأثير من خلال

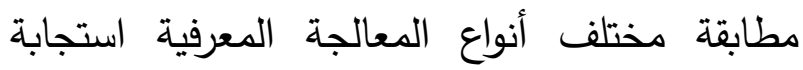
لبيئات المهام المختلفة، حيث تعمل المرونة المعرفية كآلية معقولة تؤثر على التبديل بين نوعي المعالجة

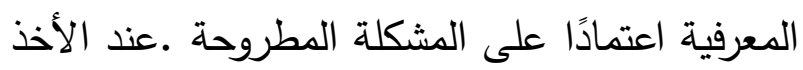
بعين الاعتبار التفاعل الثلاثي بين المرونة المعرفية

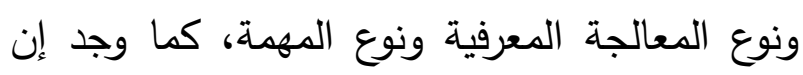
المديرين ذوي المرونة المعرفية العالية يعكسون

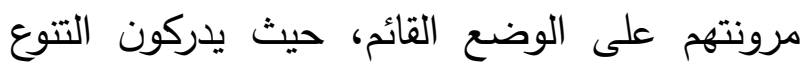
ويقدرونه في وجهات النظر ، ويدمجون هذا التوع في عمليات اتخاذ القرار الخاصة بهم. من خلال تقييم التنوع، كما أنهم أكثر عرضة للتغلب على الجمود.

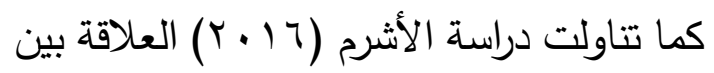
المرونة الاستراتيجية وفعالية اتخاذ القرار، وقد بلغت العينة V01 أكاديميا بالجامعة الإسلامية وجامعة وفعالهاد الأقصى، وقد توصلت النتائج إلى وجود علاقة الإسلة ودئ ارتباطية موجبة بين المرونة الاستراتيجية ودرجة مستوى فاعلية اتخاذ القرار .

كما هدفت دراسة كل من بيكل واولوبي \& Ulubey المعرفية واستراتيجيات المواجهة التي تتناول العديد من استراتيجيات التعامل مع المواقف سواء إيجابية او سلبية أو حتى تجنبيه أي عدم المواجهة وعدم اتخاذ

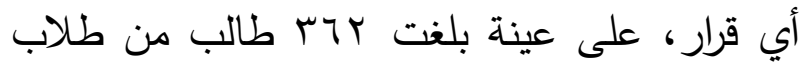


ب-هل توجد فروق ذات دلالة إحصائية في

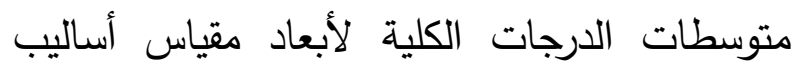

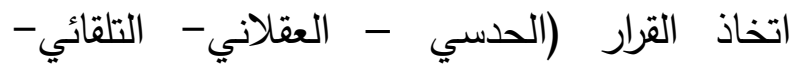
الاعتمادي- التجنبي) بين الذكور والإناث من طلبة

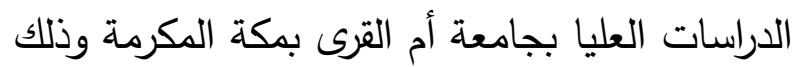
في حالة وجود العمل الإداري من عدمه؟

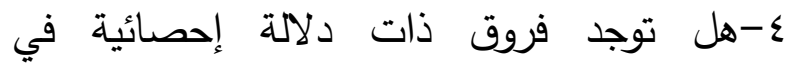
متوسطات الدرجات الكلية لأبعاد مقياس المرونة المعرفية بين الذكور والإناث من طلبة الدراسات العليا بجامعة أم القرى بمكة المكرمة وذلك في حالة وجود لإند

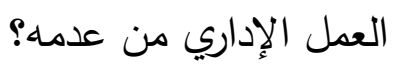
0-هل يمكن تحديد حجم الاسهام النسبي للمرونة المعرفية المتمثلة في (البدائل المعرفية- الرقابة أو الدئ

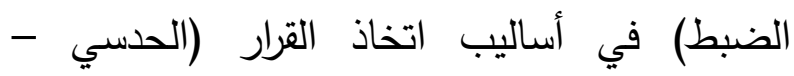
العقلاني- التلقائي - الاعتمادي- التجنبي) لدى طلبة الدراسات العليا بجامعة أم القرى؟ أهداف البحث:

يهدف البحث الحالي إلى التعرف على: ا-تحديد كل من أساليب اتخاذ القرار (الحدسي العقلاني- التلقائي - الاعتمادي- التجنبي) وابعاد المرونة المعرفية (البدائل المعرفية- الرقابة أو الضبط) الأكثر استخداماً لدى طلبة الدراسات العليا بجامعة أم القرى تبعا للدرجة العلمية والنوع والعينة ككل. r- معرفة العلاقة ذات الدلالة الإحصائية بين أساليب اتخاذ القرار (الحسسي - العقلاني - التلقائي - لعائية
إلى النظر في الاحتمالات المختلفة، والتي تتطلب تفكيرًا نشطًا في للحكم على مدى ملاءمتها (Diamond, 2013; Raes, Heijltjes, Glunk, .\& Roe, 2011) وقد ربطت الدراسات المرونة بصور مختلفة

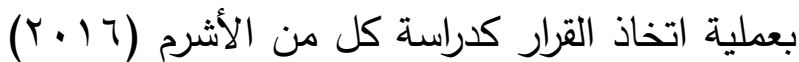
وصالح (1/ • ب)، كما ربطت دراسة لورينومارتنيز Laureiro-Martínez \& Brusoni وبروسوني

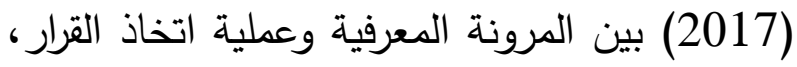
إلا انه لم توجد -في حدود علم الباحثة- دراسات

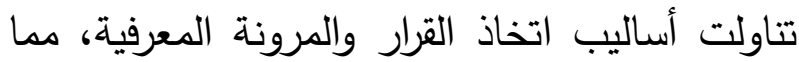
يدعم توجه البحث الحالي في دراسة حجم الاسهام النسبي للمرونة المعرفية في أساليب اتخاذ القرار لاى لدى لدانه طلبة الدراسات العليا بجامعة أم القرى. وعليه فِانِ البحث الحالي يسعى للإجابة عن التساؤلات التالية: 1-هل يمكن تحديد كل من أساليب اتخاذ القرار

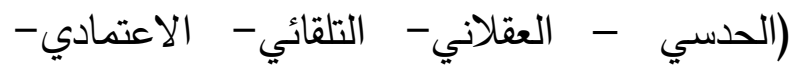
التجنبي) وابعاد المرونة المعرفية (البدائل المعرفية- الاعيدية

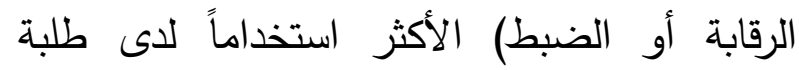
الدراسات العليا بجامعة أم القرى تبعا للدرجة العلمية

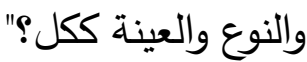
r-هل توجد علاقة ذات دلالة إحصائية بين أساليب

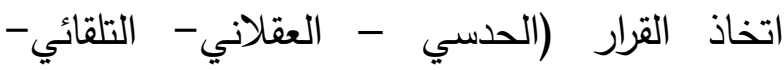
الاعتمادي- التجنبي) والمرونة المعرفية وابعادها

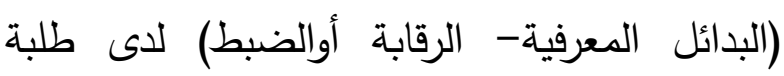

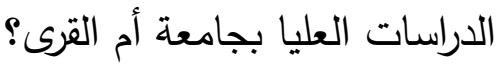


يُقترض أن لديهم القدرة على التعامل مع الضغوط البحثية والادارية وضغوط الحياة بواقعية والبعد عن لفن الفي الافكار الجامدة غير المرنة والقدرة على اتخاذ القرارات الرشيدة، في ظل العديد من التغيرات الثقافية والاقتصادية والعالمية الصعبة التي تمثل ضغوطناً نفسية واجتماعية واقتصادية شديدة على المجتمع ككل، لذلك تعتبر المرونة المعرفية مطلب مهم لهذه الفئة لأنهم يمثلون شباب هذا الوطن، الذين هم ثروة وعماد تطور الأوطان، لذلك من المهم معرفة أساليب اتخاذ القرار وعلاقتها بالمرونة المعرفية لديهم. r-كما يسهم البحث الحالي في الأثراء الأدبي لعلم النفس بصورة عامة، وعلم النغس التربوي بصورة خاصة في العلاقة بين أساليب اتخاذ القرار والمرونة المعرفية، وذلك في ضوء قلة الدراسات التي تتناول تحديد حجم العلاقة بين هذه المتغيرات.

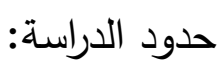
-الحدود الموضوعية: تتحدد بالموضوع الذي تتناوله وهو أساليب اتخاذ القرار وعلاقتها بالمرونة المعرفية لاى طلبة الدراسات العليا بجامعة أم القرى (ذكور واناث) بمكة المكرمة. -الحدود البشرية: لاى طلبة الدراسات العليا بكلية التربية بجامعة أم القرى (ذكور واناث).

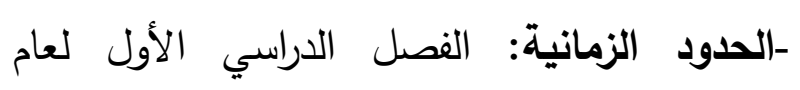
. $1 \leq \leqslant r-1 \leq \leqslant 1$ -الحدود الادائية: تتحدد نتائج الدراسة بطبيعة الأدوات المستخدمة وهي مقياس أساليب اتخاذ القرار
الاعتمادي- التجنبي) والمرونة المعرفية وابعادها (البدائل المعرفية- الرقابة أوالضبط) للى طائل الدراسات العليا بجامعة أم القرى.

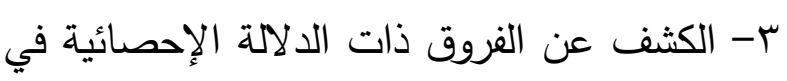
متوسطات الدرجات الكلية لأبعاد مقياس أساليب الإلي

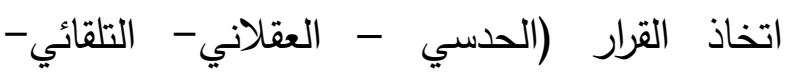
الاعتمادي- التجنبي) بين الذكور والإناث من طلبة الدراسات العليا بجامعة أم القرى بمكة الدكرمة وذلك الكالك في حالة وجود العمل الإداري من عدمه. ع-الكشف عن الفروق ذات الدالالة الإحصائية في متوسطات الدرجات الكلية لأبعاد مقياس المرونة المعرفية بين الذكور والإناث من طلبة الدراسات العليا بجامعة أم القرى بمكة الدكرمة وذلك في حالة وجود الأناث العمل الإداري من عدمه. ه-إككانية تحديد حجم الاسهام النسبي للمرونة

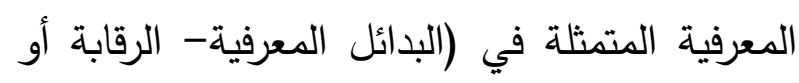

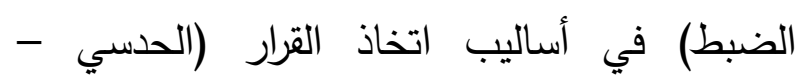
العقلاني - التلقائي - الاعتمادي- التجنبي) لاى طلبة الدراسات العليا بجامعة أم القرى. أهمية البحث البحثيات تتضح أهمية البحث الحالي فيما يلي: ا-يعمل هذا البحث على استخدام عينة تمثل طلبة لئل

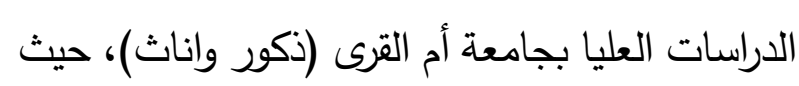
تتعرض للكثير من الضغوط و المطالب البرات البحثية والإدارية المتعلقة بكل من القسم والكلية والجامعة، ناهيك عن الضغوط العائلية والاجتماعية، لذلك ولكية 
ه-الأسلوب التجنبي Avoidant Style: يوصف بأنه محاولات تجنب اتخاذ القرار متى ما كان ذلك لجن ممكنا.

وتُعرف إجرائياً بإنها الدرجة التي تحصل عليها

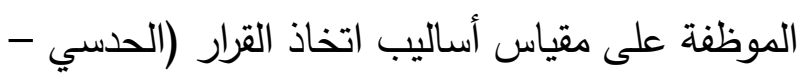
العقلاني - التلقائي - الاعتمادي -التجنبي) المستخدم الفئه في هذه الدراسة.

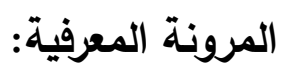

هي القدرة على تحويل أو تغيير المجموعات المعرفية للتكيف مع المتغيرات البيئية المتغيرة (Dinnes \& Vander wel,2010,242) وتتمثل قدرات المرونة المعرفية في قرتين وهي

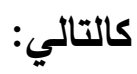
the Alternatives subscale البدائل الفرعية: وتعنى القدرة على تقديم تقسيرات مختلفة وحلول بديلة ومتعددة للمواقف المتغيرة او الصعبة.

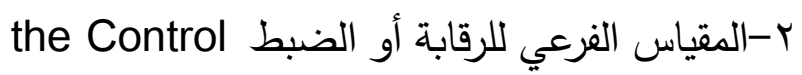
subscale وتعني القدرة على إدراك المواقف الصعبة الصنية وضبطها والتحكم فيها. منهج البحث

استخدمت الدراسة الحالية المنهج الوصفي (الارتباطي/الفارقي)، وذلك للإجابة عن تساؤلات الدراسة. مجتمع البحث تكون مجتمع الدراسة من جميع طلبة الدراسات العليا

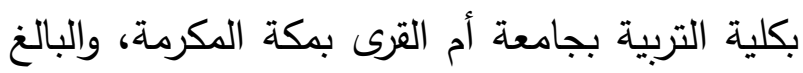

لسكوت وبروس Scott \& Bruce (1995) ومقياس المرونة المعرفية CFI لكل من دينيس وفاندر ويل .Dennis \& Vander wel مصطلحات البحث أساليب اتخاذ القرار هي "نمط استجابي معتاد ومتعلم يظهره الفرد عندما يواجه موقف قرار وهذه الأساليب ليست سمات شخصية وإنما ميل واستعداد للاستجابة بطريقة مؤكدة Scott

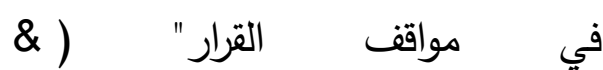
.(Bruce, 1995,p. 820 وتتمثل أساليب اتخاذ القرار فيما يلي: 1-الأسلوب الحدسي Intuitive Style: يوصفئ الانتباه للتفاصيل أثناء تدقيق المعلومات أكثر من

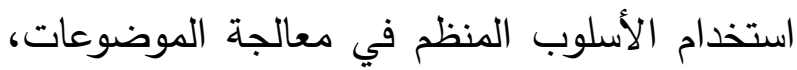
كما يصف أيضا" بالاعتماد على المشاعر والهواجس.

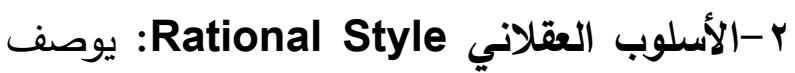
بالبحث الثامل عن المعلومات وضع قائمة بالبدائل والتتييم المنطقي لها. ب-الأسلوب التلقائي Spontaneous Style: يوصف بأنه الثعور الفوري والرغبة المباشرة في الاخول في معالجات اتخاذ القرار بأسرع وقت ممكن. צ-الأسلوب الاعتمادي Dependent Style: يوصف بأنه البحث عن النصيحة والإشاد من الاعمادي الآخرين قبل القيام باتخاذه. 
الأصلية للمقياس مع الترجمة على مجموعه من المتخصصين في علم النفس، ومن ثم أُجريت التعديلات على البنود التي أشاروا بإجراء تعديلات عليها. حيث تمت إضافة ب بنود لكل مقياس فرعي من مقاييس أساليب اتخاذ القرار، ما عدا الأسلوب الحدسي والذي أضيف إليه V بنود وذلك لعدم وجود اتفاق كامل حول معناه الدقيق ولتعدد سياقاته. وتم حساب ثبات المقياس باستخدام كل من الاتساق الداخلي بطريقة الفا كرونباخ، وكانت معاملات الثبات مرتفعة. وتمت إعادة التطبيق بفاصل زمني قدره 10 يوماً وكانت معاملات الارتباط بين

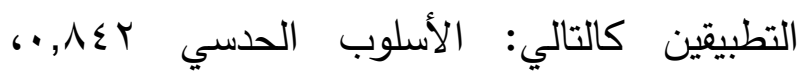
الأسلوب العقلاني: جـر, •، الأسلوب التلقائي:  التجنبي V00, • ، كما تم التحقق من صدق المقياس باستخدام التحليل العاملي فتم تحديد خمسة عوامل فسرت 9,0V ؛ \% من التباين الكلي، وقد أخذ بالتشبعات التي فوق • ع, •، وبهذا الإجراء أصبح عدد

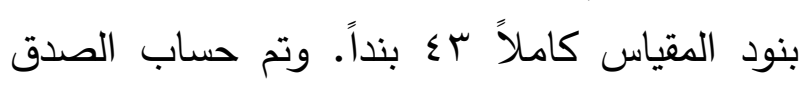
التكويني وذلك من خلال حساب معامل الارتباط بين مقياس أساليب اتخاذ القرار ومقياس وجهة الضبط، وأثارت النتائج إلى ارتباط الأسلوب العقلاني ارتباطاً سالباً دالاً بوجهة الضبط، كما ارتبط كلُ من الأسلوبين التجنبي والاعتمادي ارتباطاً إيجاباً دالاً بمقياس وجهة الضبط، وهذا يتفق مع ما توصلت إليه نتائج الدراسات الأجنبية التي تمت على المقياس.

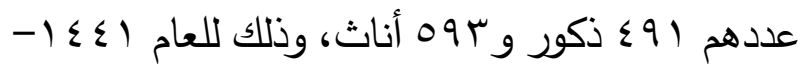
هـ $\leqslant \leqslant Y$ عينة البحث العينة الاستطلاعية

اختيرت العينة الاستطلاعية بطريقة عشوائية من طلبة الدارسات العليا بكلية التربية جامعة أم القرى،

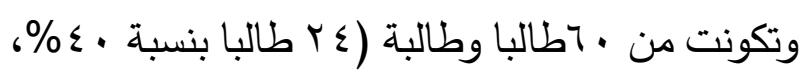

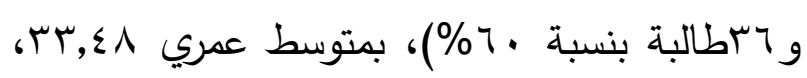
وانحراف معياري ه r, واستخدمت درجات هذه العينة في تقنين أدوات الدراسة. العينة الأساسية تكونت العينة الأساسية من هبrسالبا وطالبة من طلبة الدراسات العليا بجامعة أم القرى (ب ـ ا طالبا

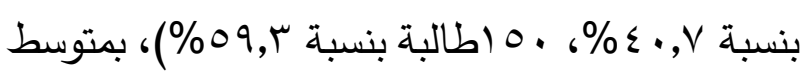
عمري 7,سז، وانحراف معياري .0,7، واستخدمت درجات هذه العينة في الاجابة على تساؤلات الدراسة. أدوات البحث

أولاً: مقياس أساليب اتخاذ القرار: قام بإعداد هذا المقياس كل من سكوت وبروس Scott \& Bruce (1995) استناداً على نموذج أساليب اتخاذ القرار في المجال المهني لصاحبه هارمان Harren. ولقد أظهر التحليل العاملي الاستكثافي خمسة عوامل وهي: العقلاني، الحدسي، الاعتمادي، التجنبي، والتلقائي. وقد احتوى كل بند على مب عبارة يجيب عليها المفحوص وفقاً لمدرج خماسي. وقد تمت ترجمة بنود المقياس من قبل العتيبي (9 . . ب)، وتم عرض النسخة 
ولاستخدامه في هذه الدراسة تم التحقق من صدق المقياس، ثم حساب معاملات الارتباط بين درجة كل وثبات المقياس على عينة استطلاعيه بلغت . ج طالباً عبارة من عبارات المقياس والبعد الذي تنتمي إليه،

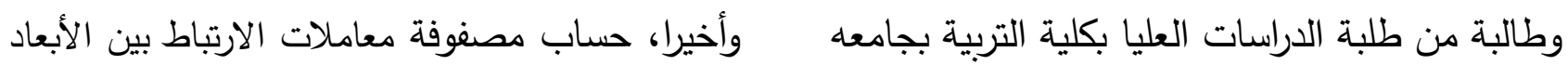

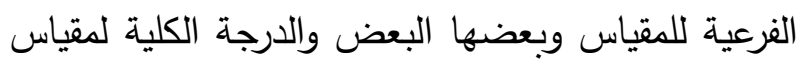
أم القرى، حيث تم حساب معاملات الارتباط بين درجة مانه

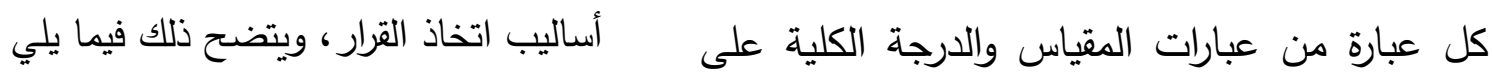
جدول ا معاملات الارتباط بين درجة كل عبارة من عبارات مقياس أساليب اتخاذ القرار

\begin{tabular}{|c|c|c|c|}
\hline معامل الارتباط & رقم العبارة & معامل الارتباط & رقم العبارة \\
\hline ***,OYI & rr & ***,$\nearrow \leq V$ & 1 \\
\hline$* *, 0 \leq r$ & $r \varepsilon$ & ***,YYI & $r$ \\
\hline ***, • & ro & ***, • O Y & $r$ \\
\hline ***, ๑ 97 & ry & *** , 701 & $\varepsilon$ \\
\hline ***,,$\vee ৭ \bullet$ & $r v$ & ***, • ๑ • & 0 \\
\hline *** , $\{0$. & $r \wedge$ & 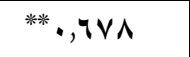 & 9 \\
\hline *** , ฯ ^. & rq & $* *, \subseteq Y Y$ & V \\
\hline 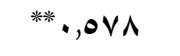 & r. & ***, • & $\Lambda$ \\
\hline *** •,£V. & ו & ***, •\{Y। & 9 \\
\hline ***, ,००^ & Mr & $* *, 01 \varepsilon$ & 1. \\
\hline *** • & ب & *** , Y० & 11 \\
\hline ***. ๆ9 & $r \varepsilon$ & ***, • & Ir \\
\hline ***, OYV & Mo & $* *, 019$ & ir \\
\hline ***,,$\leqslant 00$ & ry & 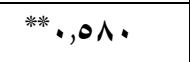 & $1 \varepsilon$ \\
\hline *** • $\neg \wedge 9$ & rv & *** • & 10 \\
\hline *** • $\varepsilon$ Or & rᄉ & ***, •r. & 17 \\
\hline 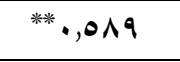 & rq & ***, • r Y & iv \\
\hline ***, ๑९. & $\varepsilon$. & *** ., 007 & 11 \\
\hline *** •, $\{71$ & \& & $* *, \bullet \wedge ৭$ & 19 \\
\hline q & $\varepsilon r$ & ***,$\vee \vee \bullet$ & $r$ \\
\hline \multirow[t]{2}{*}{ ****,,$V \cdot r$} & $\varepsilon r$ & ***, 717 & YI \\
\hline & & ***,, $0 \leq \Gamma$ & $r r$ \\
\hline
\end{tabular}




$$
\text { سميرة محارب العتيبي }
$$

جدول r معاملات الارتباط بين درجة كل عبارة والارجة الكلية للبعد الذي

تنتمي إليه لمقياس أساليب اتخاذ القرار

\begin{tabular}{|c|c|c|c|}
\hline معامل الارتباط & رقب & معامل الارتباط & رقم العبارة \\
\hline \multicolumn{4}{|c|}{ الأسلوب الحدسي } \\
\hline ****,, T $\leqslant \leq$ & $r \varepsilon$ & ${ }^{* * *} \cdot, \wedge 10$ & $r$ \\
\hline ****, $\cdot$ 人 99 & rq & ***,, 799 & 0 \\
\hline ****, $\vee \vee \curlyvee q$ & ז & ***, & $\wedge$ \\
\hline$*^{*} \cdot, \wedge \leq 1$ & rq & ***,,$\vee q \leq$ & ir \\
\hline 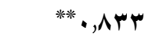 & $\varepsilon r$ & ***, & 11 \\
\hline & & ${ }^{* * *}$, VYY . & M \\
\hline \multicolumn{4}{|c|}{ الأسلوب العقلاني } \\
\hline ***, •, १ & $r \wedge$ & ${ }^{* * * *} \cdot, 119$ & 1 \\
\hline$* * \cdot, A \cdot 9$ & rr & ${ }^{*} * *, v \otimes \wedge$ & $v$ \\
\hline ***, & rᄉ & ${ }^{* * *} \cdot, \mathrm{V} T \mathrm{~V}$ & ir \\
\hline ***, & $\varepsilon r$ & ***, TVI & iv \\
\hline & & ***, VYY & $r r$ \\
\hline \multicolumn{4}{|c|}{ الأسلوب التلقائي } \\
\hline ***, , 9.8 & $r v$ & ***, & 9 \\
\hline ***, V৭१ & Mr & ת & 11 \\
\hline${ }^{* * *} \cdot$, ᄉ 70 & rv & ${ }^{* * *} \cdot, V \vee Y$ & 17 \\
\hline & & $* *, 799$ & rY \\
\hline \multicolumn{4}{|c|}{ الأسلوب الاعتمادي } \\
\hline${ }^{* * *}, \mathrm{~V} \vee \wedge \leq$ & ro & ${ }^{* * *} \cdot$, 11 & $r$ \\
\hline ***, V V V V & $r$. & ${ }^{* * * *} \cdot, \leqslant 0 \wedge$ & 9 \\
\hline${ }^{*} *$ *, VYA & po & ***, & $1 \varepsilon$ \\
\hline${ }^{*} *, *, v \cdot V$ & $\varepsilon$. & ***, & 19 \\
\hline \multicolumn{4}{|c|}{ الأسلوب التجنبي } \\
\hline ***, •, Q Y & rq & ${ }^{* * *} \cdot, \mathrm{V} \otimes \wedge$ & $\varepsilon$ \\
\hline ***,,$\uparrow \wedge$. & r & ${ }^{* * *} \cdot$, AYr & 1. \\
\hline${ }^{* * * *}, \vee \vee \wedge \varepsilon$ & my & ${ }^{* * *} \cdot$, АҮA & 10 \\
\hline 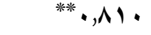 & \&1 & ${ }^{* * *}$, , VA V & $r$. \\
\hline
\end{tabular}

جدول مصفوفة معاملات ارتباط الأبعاد فيما بينها والدرجة الكلية لمقياس أساليب اتخاذ القرار

\begin{tabular}{|c|c|c|c|c|c|c|}
\hline الارجة الكلية & التجنبي & الأستملوبي & الأسلوب & العقلاني & الأسلوب & البعد \\
\hline 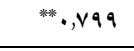 & 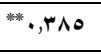 & ***, • \& Y V & $* *, 700$ & ****.,$\leqslant$ Y & 1 & الأسلوب الحلسي \\
\hline ***,, ४V & ***, & ***, • १९ & $* *, r \wedge q$ & 1 & - & الأسلوب العقلاني \\
\hline ***., จ9 & ***.,, १V & $* * ., \leqslant 99$ & 1 & - & - & الأسلوب التلقائي \\
\hline ***, , VV. & $* *, \bullet \wedge \bullet$ & 1 & - & - & - & الأسلوب الاعتمادي \\
\hline$* *, v \leqslant \Lambda$ & 1 & - & - & - & - & الأسلوب التجنبي \\
\hline
\end{tabular}


يتضح من الجداول السابقة أن جميع معاملات الارتباط موجبة ودالة احصائيا مما يشير الى توافر شروط الاتساق الداخلي لمقياس أساليب اتخاذ القرار . لن. كما تم حسـاب ثبات المقياس من خـلال استخدام معامل ألفــــا للثبات (ألفـا كرونبـاخ) والتجزئـة النصفية بطريقة (سبيرمان - بارون، وجتمـان)، ويتضح ذلك فيما يلي: جدول ؛ معاملات ثبات مقياس أساليب اتخاذ القرار

\begin{tabular}{|c|c|c|c|c|}
\hline \multirow[t]{2}{*}{ معامل ألفا } & \multicolumn{2}{|r|}{ التجزئة النصفية } & \multirow[t]{2}{*}{ البعد البع } & \multirow[t]{2}{*}{ e } \\
\hline & جتمان & سبيرمان برون & & \\
\hline$\cdot, 9 \cdot \varepsilon$ & •, QYr & - qur & الأسلوب الحدسي & 1 \\
\hline$\cdot, \wedge \circ 9$ & -,Vq & • & الأسلوب العقلاني & r \\
\hline$\cdot, 9 \cdot 1$ &., $91 \mathrm{~V}$ &., 919 & الأسلوب التلقائي & $r$ \\
\hline - A & •,vq & 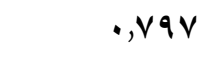 & الأسلوب الاعتمادي & $\varepsilon$ \\
\hline$\cdot, 9 \cdot 1$ & - $\vee \vee 99$ & $\cdot, \wedge \cdot 1$ & الأسلوب التجنبي & 。 \\
\hline., $91 \mathrm{~V}$ & - 9ry & $\cdot, q Y V$ & \multicolumn{2}{|c|}{ مقياس أساليب اتخاذ القرار } \\
\hline
\end{tabular}

متعددة للحالات الصعبة. والتي تحتوي على . 1. بندا، ونتيجة تحليلات صلاحية المحتوى المختلفة ومن ضمنها التحليل العاملي تم التوصل إلى عاملين هما

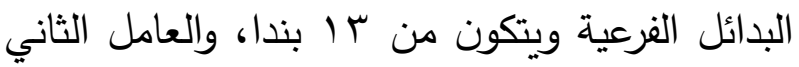

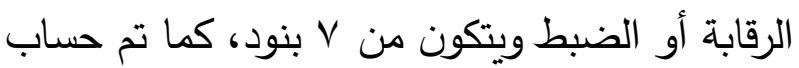
الصدق التلازمي والتقاربي مع العديد من مقاييس المرونة الأخرى، ومقاييس التأقلم والاكتئاب وجميعها أعطت معاملات ارتباط صدق جيدة مع مقياس ونعايسن المرونة المعرفية المستخدم، كما تم حساب الثبات باستخدام كل من الاتساق الداخلي بطريقة الفا لهابه

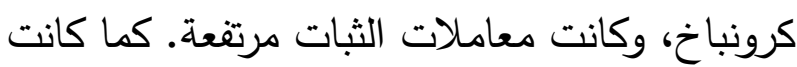

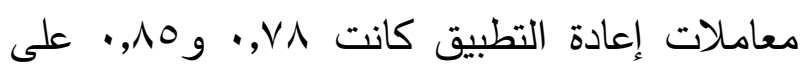

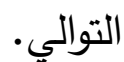

يتضح من الجدول السابق ارتفاع معاملات ثبات المقياس مع اختلاف الطرق المستخدمة في حسابه، مما يثير لثبات المقياس، وطلاحيته لاستخدامه بالدراسة الحالية. ثانياً: مقياس المرونة المعرفية: قام بإعداد هذا المقياس كل من دينيس وفاندر

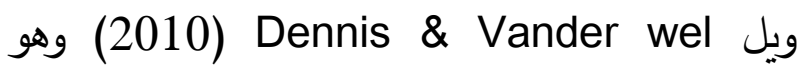
مقياس تقرير ذاتي موجز لنوع المرونة المعرفية اللازمة للافراد للنجاح، وقد تم تصميم هذا المقياس لقياس ثلاثة جوانب من المرونة المعرفية: (أ) الميل إلى هيل تصور المواقف الصعبة كما يمكن السيطرة عليها، (ب) القدرة على إدرالك تفسيرات بديلة متعددة للحياة والسلوك البشري، (ج) القدرة على توليد حلول بديلة 
ولاستخدامه في هذه الدراسة تم التحقق من المقياس والدرجة الكلية علي المقياس، ثم حساب صدق وثبات المقياس على عينة استطلاعية بلغت معاملات الارتباط بين درجة كل عبارة من عبارات

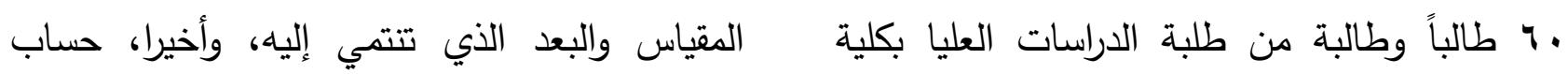
التربية بجامعه أم القرى، حيث تم حساب صدق مصفوفة معاملات الارتباط بين الأبعاد الفرعية

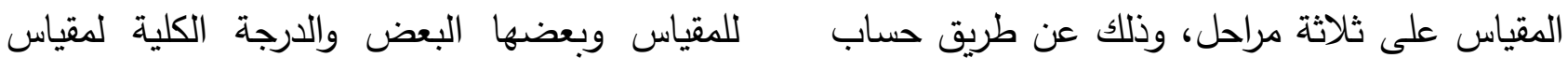

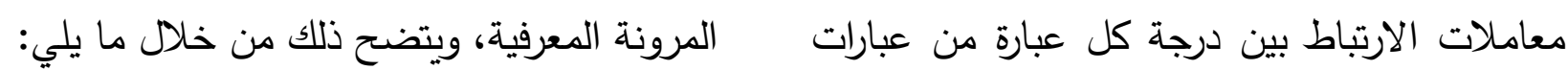
جدول ه معاملات الارتباط بين درجة كل عبارة من عبارات مقياس المرونسة كبـة

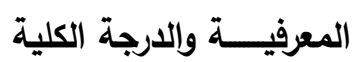

\begin{tabular}{|c|c|c|c|}
\hline معامل الارتباط & رقم البند & معامل الارتباط & رقم البند \\
\hline ****,,$V \cdot\{$ & 11 & ***,$\pi \leq r$ & 1 \\
\hline ***, , YYY & ir & *** •, ๆ9 & $r$ \\
\hline ***, VYr & ir & ***, •, १ & $r$ \\
\hline ***,, 019 & $1 \leq$ & 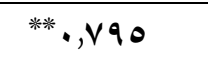 & $\varepsilon$ \\
\hline ****,,$\Lambda \cdot r$ & 10 & ***,$V \oslash \leq$ & 0 \\
\hline ***,,$v \cdot q$ & 17 & *., • צ & 9 \\
\hline 茟,人川 & iv & ***, $\vee \vee 99$ & v \\
\hline 档,,$V \bullet q$ & 11 & *.,YY & $\wedge$ \\
\hline ****, •Vฯ & 19 & ****,$\wedge \leq 0$ & 9 \\
\hline ***, VY I & $r$. & ***,, $0 \leq 1$ & 1. \\
\hline
\end{tabular}

جدول \ معاملات الارتباط بين درجة كل عبارة والارجة الكلية للبعد الذي تتنمي إليه لمقياس المرونــة المعرفيــة

\begin{tabular}{|c|c|c|c|c|c|}
\hline \multicolumn{2}{|c|}{ الرقابة أو الضبط } & \multicolumn{4}{|c|}{ البدائل المعرفية } \\
\hline معامل الارتباط & رقم - ل ع & معامل & رقم العبارة & معامل & رقم \\
\hline & العبارة & الارتباط & & الارتباط & العبارة \\
\hline "**, & $r$ & 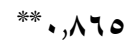 & it & ***, $\vee \backslash \wedge$ & 1 \\
\hline$* *, \wedge \leqslant 4$ & $\varepsilon$ & ${ }^{* *} \cdot, V \leqslant V$ & $1 \varepsilon$ & ***, Irv & $r$ \\
\hline **, & $v$ & ***,., ToV & 17 & "***, & 。 \\
\hline ***,VY\& & 9 & ${ }^{* * *} \cdot \wedge \cdot \wedge$ & 11 & ${ }^{* * *}$, ,०人4 & 4 \\
\hline ***,ATV & 11 & ***,, V1q & 19 & ${ }^{* * *} \cdot$, , 9 १ & $\wedge$ \\
\hline ***, & 10 & $* *, v \leqslant q$ & r. & ${ }^{* * *}, r V \Gamma$ & 1. \\
\hline "**, & iv & & & 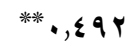 & ir \\
\hline
\end{tabular}


جدول V مصفوفة معاملات ارتباط الأبعاد فيما بينها والدرجة الكلية لمقياس المرونة المعرفية

\begin{tabular}{|c|c|c|c|}
\hline الارجة الكلية لمقياس & الضبط الرقابة & البعرفية & البعد \\
\hline ***,人ฯ & ***, TVY & - & البدائل المعرفية \\
\hline ***, 900 & - & ***, , TV r & الضبط \\
\hline
\end{tabular}

كما تم حساب الثبات من خلال استخدام كرونباخ) والتجزئـة (أ) النصفية بطريقة سبيرمان - بارون وجتمـان، وذلك
يتضح من الجداول السابقة أن جميع معاملات الارتباط موجبة ودالة احصائيا مما يشير الى توافر شروط الاتساق الداخلي لمقياس المرونة المعرفية.

\section{كما يلي:}

جدول ^ معاملات ثبات مقياس المرونة المعرفية

\begin{tabular}{|c|c|c|c|c|}
\hline \multirow{2}{*}{ ألفاا } & \multicolumn{2}{|r|}{ التجزئة النصفية } & \multirow[t]{2}{*}{ البعد } & \\
\hline & جتمان & برون & & \\
\hline ك • • & • A १ & ש & البدائل المعرفية & 1 \\
\hline$\cdot, 9 \cdot r$ & 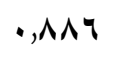 & - 9 9 9 & الرقابة أو الضبط & r \\
\hline - $9 \mathrm{PV}$ & $\cdot, 9 \leqslant r$ & . $9 \leqslant \Psi$ & جة الكلية للمقياس & \\
\hline
\end{tabular}

استخداماً لاى طلبة الدراسات العليا بجامعة أم القرى تبعا للارجة العلمية والنوع والعينة ككل؟" للإجابة عن هذا السؤال تم حساب المتوسطات الحسابية والانحرافات المعيارية (لأساليب اتخاذ القرار (الحدسي- العقلاني - التلقائي - الاعتمادي- التجنبي) وابعاد المرونة المعرفية (البدائل المعرفية- الرقابة أو

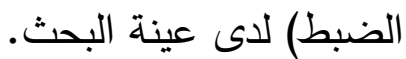

يتضح من الجدول السابق ارتفاع معاملات ثبات المقياس، مما يثير لثبات المقياس، وصلاحيته ل لاستخدام بالدراسة الحالية. نتائج البحث نتيجة السؤال الأول والذي ينص على "هل يمكن تحديد كل من أساليب

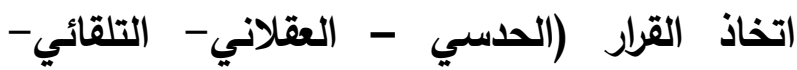
الاعتمادي- التجنبي) وابعاد المرونة المعرفية (البدائل المعرفية- - الرقابة أو الضبطي) الأكثر 
جدول 9 المتوسطات الحسابية والانحرافات المعيارية لأساليب اتخاذ القرار، وأبعاد المرونة المعرفية لدى طلبة الدراسات العليا بجامعة أم القرى (ذكور واناث - ماجستير ودكتوراة- والعينة الكلية)

\begin{tabular}{|c|c|c|c|c|c|c|c|c|}
\hline \multicolumn{2}{|c|}{ مقياس البدائل المعرفية } & \multicolumn{5}{|c|}{ مقياس أساليب اتخاذ القرار } & & \multirow[t]{3}{*}{ 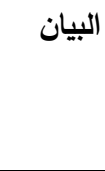 } \\
\hline الرقابة أو & البدائل & الأسلوب & الأسلوب & الأسلوب & الأسلوب & الأسلوب & & \\
\hline الضبط & المعرفية & التجنبي & الاعتمادي & التلقائي & العقلاني & الحسسي & & \\
\hline$\varepsilon, 7 V$ & $0,0 Y$ & r,AY & T,YY & $r, \diamond 0$ & r,qY & r,94 & المتوسط الحسابي & \multirow[t]{2}{*}{ ذ ذكور } \\
\hline I,YY & $\cdot, \mathrm{V}_{0}$ & • & $\cdot, 79$ & $\cdot, v^{\mu}$ &., 09 & $\cdot, \mathrm{V} \mu$ & الانحراف المعياري & \\
\hline$\varepsilon, 04$ & 0,09 & Y,TV & ه ק, & $r, 7)$ & $\varepsilon, 1$ & 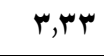 & المتوسط الحسابي & \multirow[t]{2}{*}{ اناث } \\
\hline $1, Y \wedge$ & • & $\cdot, \wedge$ & $\cdot, v$. & $\cdot, 19$ & $\cdot, \leqslant \wedge$ & $\cdot, v_{1}$ & الانحراف المعياري & \\
\hline$\varepsilon, 70$ & 0,04 & $r, V \leq$ & $r, r \cdot$ & Y,० & $\varepsilon, \cdot \varepsilon$ & $r, 1 \leq$ & المتوسط الحسابي & \multirow[t]{2}{*}{ ماجستير } \\
\hline $1, r_{0}$ & $\cdot, \wedge \varepsilon$ & $\cdot, \wedge 0$ & $\cdot, V Y$ & $\cdot, \wedge \uparrow$ & $\cdot, 0 \mathrm{~V}$ & $\cdot, v a$ & الانحراف المعياري & \\
\hline$\varepsilon$, Or & 0,07 & $r, V Y$ & $r, Y \Lambda$ & r,70 & $r, 99$ & $r, r \cdot$ & المتوسط الحسابي & \multirow[t]{2}{*}{ دكتوراه } \\
\hline $1, Y \wedge$ & $\cdot, \times 1$ & $\cdot, \mathrm{\vee} \wedge$ & $\cdot, 7 \mathrm{~V}$ & •, vo & $\cdot, \leqslant 0$ & r, Or & الانحراف المعياري & \\
\hline$\varepsilon, \pi Y$ & 0,07 & $r, V Y$ & $r, r \cdot$ & $r, 0 \wedge$ & $\varepsilon, \cdot Y$ & $r, 1 \Lambda$ & المتوسط الحسابي & \multirow{2}{*}{ لكلية } \\
\hline $1, Y 4$ & •,Ar & $\cdot, \wedge \varepsilon$ & $\cdot, v$. & • & ., $0 \leqslant$ & $\cdot, \mathrm{Vr}$ & الانحراف المعياري & \\
\hline
\end{tabular}

البدائل المعرفية في الترتيب الأول، ثم الرقابة أو

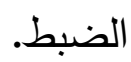

بالنسبة للعينة ككل فقد كانت أساليب اتخاذ القرار وابعاد المرونة المعرفية الأكثر استخداما هي كي كالي

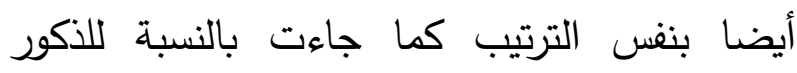
والإناث، وبالنسبة لأساليب اتخاذ القرار الأكثر استخداما لاى عينة الدراسة من طلبة الماجستير فقد تراوحت المتوسطات الحسابية لطلبة الماجستير بين

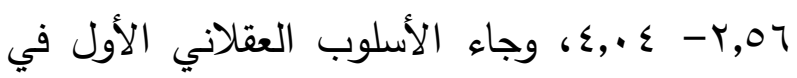

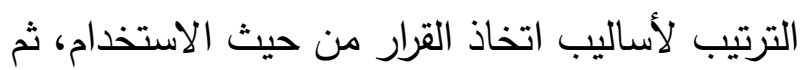

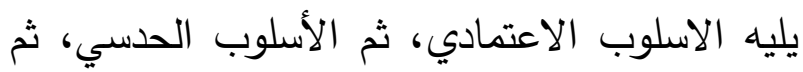
الأسلوب التجنبي بمتوسط، وأخيرا الأسلوب التلقائي.
تشير النتائج الواردة في الجدول السابق إلى ما يلي: تراوحت المتوسطات الحسابية لأساليب اتخاذ الناذ التانيان القرار الأكثر استخداما لدى عينة الدراسة من الذكور

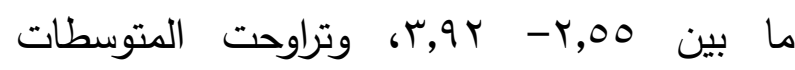

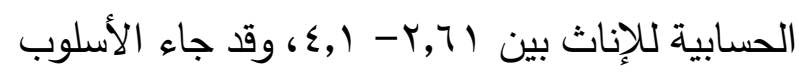
العقلاني في الترتيب الأول لأساليب اتخاذ القرار الأكثر استخداما لدى الذكور والإناث، ثم يليه الأسلوب الاعتمادي، ثم يأتي في المرتبة الثالثة

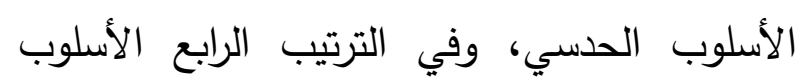

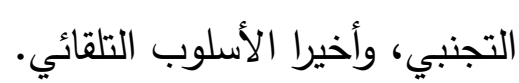
بالنسبة لأبعاد المرونة المعرفية الأكثر استخداما

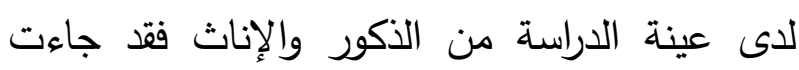


الذي ينص على "هل توجد علاقة ذات دلالة إحصائية بين أساليب اتخاذ القرار (الحسسي - العقلانيالتلقائي - الاعتمادي- التجنبي) والمرونة المعرفية وابعادها (البدائل المعرفية- الرقابة أوالضبط) لادى

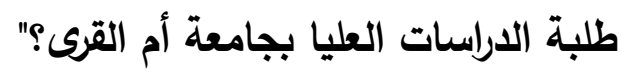

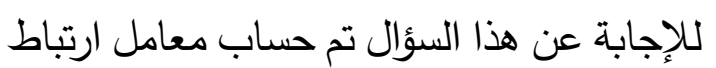

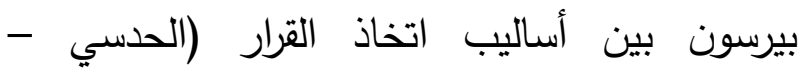
العقلاني- التلقائي - الاعتمادي- التجنبي) والمرونة المعرفية وابعادها (البدائل المعرفية- الرقابة أو الوبهي الضبط) لدى عينة البحث.
وبالنسبة لطلبة الدكتوراه فقد تراوحت المتوسطات الحسابية لأساليب اتخاذ القرار الأكثر استخداما بين

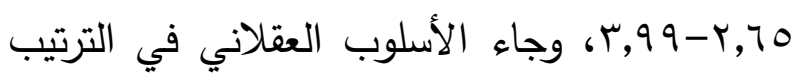

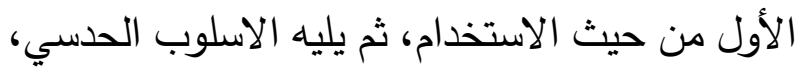
وفي الترتيب الثالث الأسلوب الاعتمادي، ثم الأسلوب التجنبي، وأخيرا الأسلوب التلقائي. وبالنسبة لأبعاد المرونة المعرفية الأكثر استخداما لدى عينة الدراسة من طلبة الماجستير

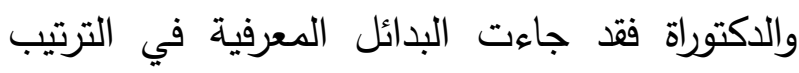
الأول، ثم الرقابة أو الضبط. نتائج السؤال الثاني جدول ـامعاملات ارتباط بيرسون بين أسائيب اتخاذ القرال (الحسبي - العقلاني- التلقائي- الاعتمادي- التجنبي) والمرونة المعرفية وابعادها (البائل المعرفية- الرقابة أوالضبط) لاى طلبة الدانية الدراسات العليا بجامعة أم القرى

\begin{tabular}{|c|c|c|c|c|c|c|}
\hline التجنبي & الاعتمادي & التلقائي & العقلاني & الحسسي & الأبعاد & العينة \\
\hline ***, & •, IVr- & 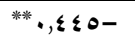 & $*^{* *} \cdot, 017$ & $\cdot, \cdot \vee \vee-$ & البدائل المعرفية & \multirow[t]{3}{*}{ ذكور } \\
\hline ****, • ০০- & ***, ケ৭१ー & ${ }^{* * * *} \cdot, \leqslant \wedge \wedge-$ & ***, $, \varepsilon, \varepsilon$ & ***,rrI- & الرقابة أو الضبط & \\
\hline$* *, 0 \leq 9-$ & ***,YTr- & ***,OHY- & ***,OYI & $*_{\bullet}, Y Y \leq-$ & الارجة الكلية & \\
\hline ***, • \7 & ***,Y०Q- & ***,, ए $9 \leq-$ & ***., & ***,YOY - & البدائل المعرفية & \multirow[t]{3}{*}{ اناث } \\
\hline ***,,$~ \& 9-$ & ***, \& $\mu_{\bullet}-$ & ${ }^{* * *}$, ,, $1-$ & ***, Y०Q & 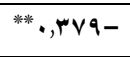 & الرقابة أو الضبط & \\
\hline ***,YIY- & ***, \&.9- & ***, ^^^०- & ***,, r. & ***,rrv- & الدرجة الكلية & \\
\hline ***,, $\leqslant$ ४ & ***,YYI- & ****, •.१- & ***,rq & *.,179- & البدائل المعرفية & \multirow[t]{3}{*}{ العينة الكلية } \\
\hline ***, $0 \leq 7-$ & ***, rV^- & ***, \& Ir- & ***, & ***, r०४- & الرقابة أو الضبط & \\
\hline ****,૦人५- & ***,,$\Gamma \leq ৭-$ & ***,, \& ११- & 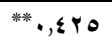 & ***,r.r- & الدرجة الكلية & \\
\hline
\end{tabular}

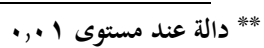

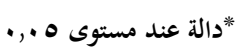

المعرفية. كما تشير النتائج أن معاملات الارتباط بين تشير النتائج بالجدول السابق إلى ما يلي:

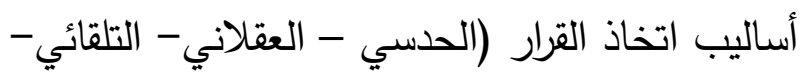
الاعتمادي- التجنبي) والرقابة أو الضبط فجميعها

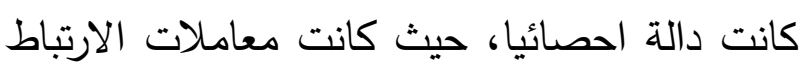

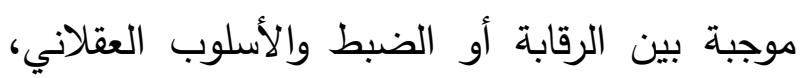

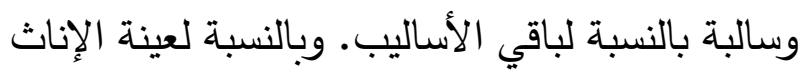

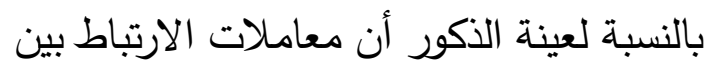
أساليب اتخاذ القرار (العقلاني- التلقائي- التجنبي) وبين البدائل المعرفية جاءت كلها دالة احصائيا، ولكنها كانت سالبة بالنسبة للأسلوب (التلقائيالتجنبي)، وموجبة بين الأسلوب العقلاني والبدائل 
التلقائي - الاعتمادي - التجنبي) بين الأكور والإناث

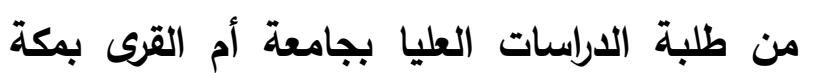

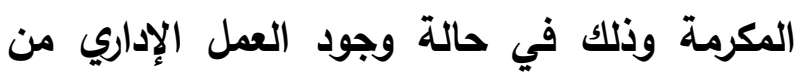

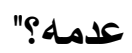

للإجابة عن هذا السؤال تم استخدام تحليل التباين متعدد الاتجاهات وكانت النتائج كما يلي:
والعينة الكلية فقد جاءت جميع معاملات الارتباط دالة احصائيا، وكانت قيمها موجبة بالنسبة للأسلوب العقلاني، وسالبة لباقي الأساليب. نتائج السؤال الثالث الأي ينص على" هل توجد فروق ذات دلالة

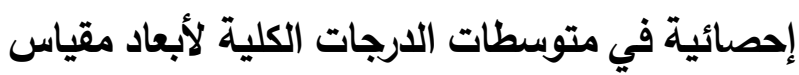
أساليب اتخاذ القرار (الحلسي - العقلاني-

جدول 11 المتوسطات الحسابية والانحرافات المعيارية للارجات الكلية لأبعاد مقياس أساليب اتخاذ القرار (الحسسي - العقلاني-

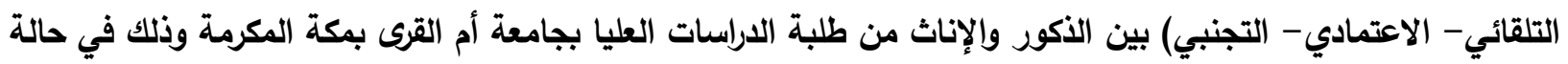

وجود العمل الإداري من عدمه لإله

\begin{tabular}{|c|c|c|c|c|c|}
\hline العدد & الانحراف المعياري & المتوسط الحسابي & النوع & العمل الاداري & أساليب اتخاذ القرار \\
\hline rq & 4 & r,q & ذكر & \multirow[t]{3}{*}{ نعم } & \multirow{9}{*}{ الأسلوب الحدسي } \\
\hline$\varepsilon$. &., 01 & r,Y & انثي & & \\
\hline 79 &., 09 & $r, I r$ & Total & & \\
\hline$V \varepsilon$ & $\cdot, \mathrm{VV}$ & Y,QV & ذكر & \multirow[t]{3}{*}{$y$} & \\
\hline 11. & $\cdot, \mathrm{V} 4$ & r, r & انثي & & \\
\hline $1 \wedge \varepsilon$ & $\cdot, \mathrm{V} \wedge$ & $r, Y$. & Total & & \\
\hline $1 . r$ & $\cdot, V \mu$ & Y,१५ & ذكر & \multirow[t]{3}{*}{ العينة الكلية } & \\
\hline 10. & $\cdot, V_{1}$ & r,rr & انثي & & \\
\hline ror & $\cdot, V r$ & $r, 1 \Lambda$ & Total & & \\
\hline rq & $\cdot, 0$ & $r, q$. & ذكر & \multirow[t]{3}{*}{ نعم } & \multirow[t]{9}{*}{ الأسلوب العقلاني } \\
\hline$\varepsilon$ & $\cdot, r v$ & $\varepsilon, 17$ & انثي & & \\
\hline 79 & $\cdot, \leqslant \leq$ & $\varepsilon, \bullet 0$ & Total & & \\
\hline$V \leq$ & זד, & $r, q \mu$ & ذكر & \multirow[t]{3}{*}{$y$} & \\
\hline 11. & . Or & $\varepsilon, \bullet$ & انثي & & \\
\hline $1 \wedge \varepsilon$ &., $0 \mathrm{~V}$ & $\varepsilon, \cdot r$ & Total & & \\
\hline $1 \cdot r$ &., $9 \leq$ & r,qץ & ذكر & \multirow[t]{3}{*}{ العينة الكلية } & \\
\hline 10. & $\cdot, \leqslant 9$ & $\varepsilon, 1$ & انثي & & \\
\hline ror & $\cdot, 0 \leq$ & $\varepsilon, \bullet$ & Total & & \\
\hline rq &., 79 & $r, \& V$ & ذكر & \multirow[t]{3}{*}{ ن نعم } & \multirow[t]{6}{*}{ الأسلوب التلقائي } \\
\hline$\varepsilon$ & $\cdot, 0 \mathrm{~V}$ & Y,YA & انثي & & \\
\hline 79 & זד, & r,ru & Total & & \\
\hline$V \varepsilon$ & $\cdot, v 4$ & Y,OA & ذكر & \multirow[t]{3}{*}{$\gamma$} & \\
\hline 11. &., 99 & $r, V r$ & انثي & & \\
\hline $11 \leqslant$ & $\cdot, \wedge \wedge$ & T,TV & Total & & \\
\hline
\end{tabular}




\begin{tabular}{|c|c|c|c|c|c|}
\hline $1 . r$ & $\cdot, V r$ & $r, \infty 0$ & ذكر & \multirow[t]{3}{*}{ العينة الكلية } & \\
\hline 10. & $\cdot, \wedge 9$ & Y,Y & انثي & & \\
\hline ror & • & $r, \otimes \Lambda$ & Total & & \\
\hline rq & $\cdot, v_{1}$ & r,Yo & ذكر & \multirow[t]{3}{*}{ 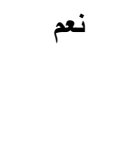 } & \multirow{9}{*}{ الأسلوب الاعتمادي } \\
\hline$\varepsilon$. & $\cdot, 79$ & $r, 19$ & انثي & & \\
\hline 99 & $\cdot, 4 \Lambda$ & r,Y Y & Total & & \\
\hline$V \varepsilon$ & $\cdot, v$. & $r, r \cdot$ & ذكر & \multirow[t]{3}{*}{ ע } & \\
\hline 11. & $\cdot, v$. & $r, \leqslant 1$ & انثي & & \\
\hline $1 \wedge \varepsilon$ & $\cdot, v$. & Tr,r & Total & & \\
\hline $1 \cdot r$ & $\cdot, 79$ & r,Y Y & ذكر & \multirow[t]{3}{*}{ العينة الكلية } & \\
\hline 10. & $\cdot, v$. & r, r & انثي & & \\
\hline ror & $\cdot, v$. & $r, r \cdot$ & Total & & \\
\hline rq & • & 9,79 & ذكر & \multirow[t]{3}{*}{ نعم } & \multirow[t]{9}{*}{ الأسلوب التجنبي } \\
\hline$\varepsilon$. & $\cdot, \vee \wedge$. & r, rA & انثي & & \\
\hline 79 & $\cdot, \wedge 1$ & $r, 01$ & Total & & \\
\hline$V \varepsilon$ & •, גז. & $r, \wedge \vee$ & ذكر & \multirow[t]{3}{*}{ لا } & \\
\hline 11. & $\cdot, \wedge \bullet$ & $r, \nabla \wedge$ & انثي & & \\
\hline $1 \wedge \varepsilon$ & $\cdot, \wedge \varepsilon$ & $r, A r$ & Total & & \\
\hline $1 \cdot r$ & • & r,AY & ذكر & \multirow[t]{3}{*}{ العينة الكلية } & \\
\hline 10. & $\cdots, \wedge \bullet$ & Y,TV & انثي & & \\
\hline ror & $\cdot, \wedge \varepsilon$ & $r, v r$ & Total & & \\
\hline
\end{tabular}

جدول ب انتائج تحليل التباين متعدد الاتجاهات تبعا للنوع والعمل الإداري على أبعاد مقياس أساليب اتخاذ القرار

\begin{tabular}{|c|c|c|c|c|c|c|c|}
\hline الجزئية & الدلالة & قيمة ف & متوسط المربعات & df & مجموع المربعات & المتغير التابع & مصدر التباين \\
\hline$\cdot, \ldots r$ & $\cdot, £ \wedge$ & $\cdot, 0.1$ & •, r०Q & 1 & •, Y०Q & الأسلوب الحدسي & \multirow[t]{5}{*}{ العمل الاداري } \\
\hline,$\ldots 1$ & $\cdot, V Y \leq$ & . Iro & $\cdot, \cdot+4$ & 1 & $\cdot,+, 4$ & الأسلوب العقلاني & \\
\hline , , rr & $\cdot, \cdot r \cdot$ & 0,01 . & r,vir & 1 & r,vir & الأسلوب التلقائي & \\
\hline$\cdot, \cdots r$ & •, rVY & - V৭ V & (, & 1 & , & الأسلوب الاعتمادي & \\
\hline •, & $\cdot, \cdot 1 \mathrm{~V}$ & $0, \vee ৭ ৭$ & $\varepsilon, . \bullet$ & 1 & $\varepsilon, \bullet$ & الأسلوب التجنبي & \\
\hline$\bullet, \bullet \leq V$ & $\cdot, \ldots 1$ & Ir,rYq & ד, & 1 & ד, & الأسلوب الحلسي & \multirow[t]{5}{*}{ النوع } \\
\hline$\cdot,+r q$ & $\cdot, \ldots v$ & $\vee, 01$. & $r, 104$ & 1 & $r, 104$ & الأسلوب العقلاني & \\
\hline$\cdot, \cdots$ & $\cdot, \wedge \leq 4$ & $\cdot, \cdot+\Lambda$ & $\cdot, \cdot Y 4$ & 1 & $\cdot,+47$ & الأسلوب التلقائي & \\
\hline$\cdot,+r$ & $\cdot, \leq 71$ & $\cdot, 0 \leq 0$ & •,YTV & 1 & •,YTV & الأسلوب الاعتمادي & \\
\hline.,+11 &., .90 & $r, \wedge)$. & 1,97r & 1 & 1,97r & الأسلوب التجنبي & \\
\hline$\cdot, \cdots$ & $\cdot, \vee \vee \wedge$ & $\bullet, \wedge$ & $\cdot, \cdot \leq 1$ & 1 & $\cdot, \cdot \leqslant 1$ & الأسلوب الحسسي & \multirow[t]{5}{*}{ العمل الاداري * النوع } \\
\hline$\cdot, \cdots r$ & $\cdot, \leqslant 09$ &., 001 & $\cdot, 101$ & 1 & $\cdot, 101$ & الأسلوب العقلاني & \\
\hline$\cdot, \cdots \wedge$ &., 100 & $r, \cdot r v$ & $1, r v r$ & 1 & $1, r v r$ & الأسلوب التلقائي & \\
\hline$\bullet, \cdots v$ & $\cdot, 1 \wedge 0$ & $1, \mathrm{VV}$ & $\cdot, \wedge ฯ \wedge$ & 1 & •,^ฯ^ & الأسلوب الاعتمادي & \\
\hline$\bullet, \cdots r$ & • & •,Vฯ & •,OHT & 1 & ש & الأسلوب التجنبي & \\
\hline
\end{tabular}


الأسلوب العقلاني بين الذكور والإناث من طلبة الدراسات العليا بجامعة أم القرى، حيث كانت قيمة لإنول ف V,01 وهي دالة عند مستوى 1.,.,.، وكانت الفروق لصالح الإناث.

ولم توجد فروق ذات دلالة احصائية في لإن متوسطات الدرجات الكلية لأبعاد مقياس أساليب

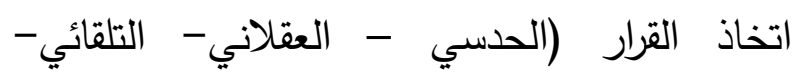
الاعتمادي- التجنبي) تعزي للتفاعل بين العمل الإداري والنوع. - الاعتماتص نتائج السؤال الرابع الذي ينص على: "هل توجد فروق ذات دلالة إحصائية في متوسطات الارجات الكلية لأبعاد مقياس المرونة المعرفية بين الأكور والإناث من طلبة

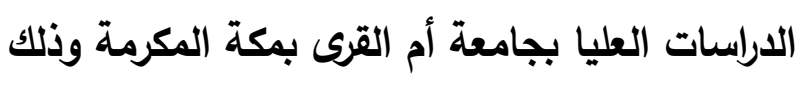

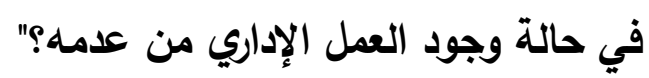
للإجابة عن هذا السؤال تم استخدام تحليل التباين متعدد الاتجاهات وكانت النتائج كما يلي: جدول با المتوسطات الحسابية والانحرافات المعيارية للارجات الكلية لأبعاد مقياس المرونة المعرفية بين الذكور

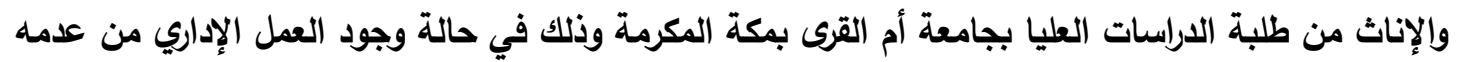

\begin{tabular}{|c|c|c|c|c|c|}
\hline العدد & الانحراف المعياري & المتوسط الحسابي & النوع & العمل الإداري & أبعاد المرونة المعرفية \\
\hline rq & $\cdot, 0$ & $0, \vee \wedge$ & ذكر & \multirow[t]{3}{*}{ نعم } & \multirow[t]{9}{*}{ البدائل المعرفية } \\
\hline$\varepsilon$. &., 01 & 0,94 & انثي & & \\
\hline 79 &., 00 & $0, \wedge \uparrow$ & Total & & \\
\hline$V \varepsilon$ & $\cdot$ •, Ar & $0, \varepsilon Y$ & ذكر & \multirow[t]{3}{*}{ ע } & \\
\hline 11. & - ,9Y & $0, \leqslant V$ & انثي & & \\
\hline $11 \leqslant$ & $\cdot, \wedge \wedge$ & $0, \leqslant 0$ & Total & & \\
\hline $1 \cdot r$ & $\cdot, \vee 4$ & $0,0 Y$ & ذكر & \multirow[t]{3}{*}{ العينة الكلية } & \\
\hline 10. & •,А५ & 0,09 & انثي & & \\
\hline ror & $\cdot$ •, Ar & 0,07 & Total & & \\
\hline rq & $1,1 \%$ & $\varepsilon, \wedge \wedge$ & ذكر & نعم & الرقابة أو الضبط \\
\hline
\end{tabular}

يتضح من الجدول السابق ما يلي: وجود فروق ذات دلالة احصائية في متوسطات درجات الأسلوب التلقائي لاى طلبة الدراسات العليا

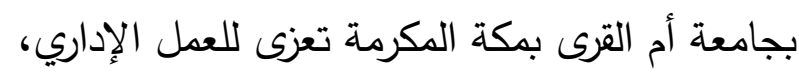

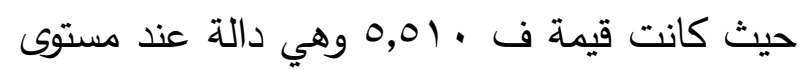

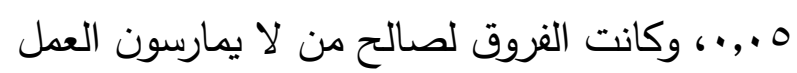

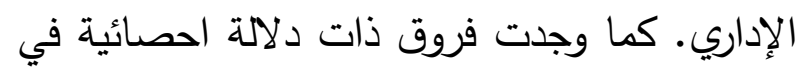

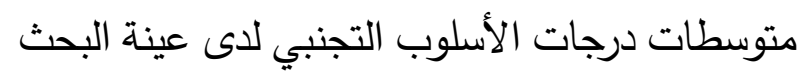
تعزى للعمل الإداري، حيث كانت قيمة ف 0, >99

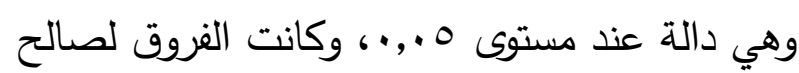
من لا يمارسون العمل الإداري. كما وجدت فروق ذات دلالة احصائية في متوسطات درجات الأسلوب الحدسي بين الذكور

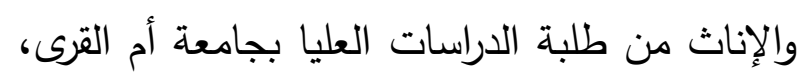

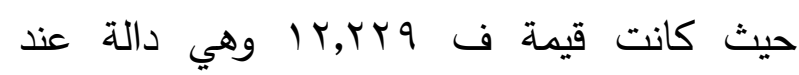

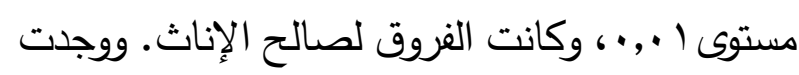
فروق ذات دلالة احصائية في متوسطات درجات 


\begin{tabular}{|c|c|c|c|c|}
\hline$\varepsilon$. & $1, r q$ & $\varepsilon, 99$ & انثي & \\
\hline 79 & $1, r \wedge$ & $\varepsilon, 9 \leqslant$ & Total & \\
\hline$V \varepsilon$ & $1, Y_{7}$ & $\varepsilon, 0 \wedge$ & ذكر & \multirow[t]{3}{*}{ V } \\
\hline 11. & $1, Y Y$ & $\leq, \leq \leqslant$ & انثي & \\
\hline $1 \wedge \varepsilon$ & $1, Y \varepsilon$ & $\varepsilon, 0$. & Total & \\
\hline $1 . r$ & I,Y & $\varepsilon, 7 V$ & ذكر & \multirow[t]{3}{*}{ العينة الكلية } \\
\hline 10. & $1, r^{9}$ & $\varepsilon, \diamond q$ & انثي & \\
\hline ror & $1, Y_{7}$ & $\varepsilon, Y Y$ & Total & \\
\hline
\end{tabular}

جدول ؛ انتائج تحليل التباين متعدد الاتجاهات تبعا للنوع والعمل الإداري على أبعاد مقياس المرونة المعرفية

\begin{tabular}{|c|c|c|c|c|c|c|c|}
\hline الجزيع & الدالة & قيمة ف & متوسط المربعات & df & المربعات & المتفير التابع & مصدر التباين \\
\hline 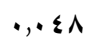 & ${ }^{,}, \ldots$ & $\mid r, \leqslant \wedge \wedge$ & $\Lambda, \cdot V r$ & 1 & $\Lambda, \cdot V \mu$ & البدائل المعرفية & \multirow[t]{2}{*}{ العمل الإداري } \\
\hline$\cdot,+r)$ & $\cdot, \cdot Y$. & $0, \leqslant 0$. & A,oro & 1 & A,oro & الرقابة أو الضبط & \\
\hline 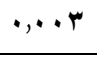 & •, $\leqslant 11$ & •, โท & •, & 1 & 9 & البدائل المعرفية & \multirow[t]{2}{*}{ النوع } \\
\hline$\cdot, \cdots$ & •, qrv & $\cdot, \ldots 7$ & $\cdot,+1$. & 1 & $\cdot,+1$. & الرقابة أو الضبط & \\
\hline$\cdot, \cdots$ & ד & •, Y II & • Irv & 1 & • & البدائل المعرفية & العمل الإداري \\
\hline 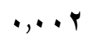 & $\cdot,\{\wedge 1$ & •, $\leqslant 99$ & •, $\mathrm{VAl}$ & 1 & •, $\mathrm{VAl}$ & الرقابة أو الضبط & النوع \\
\hline
\end{tabular}

الذكور والإناث من طلبة الدراسات العليا تعزى للتفاعل بين النوع والعمل الإداري. نتائج السؤال الخامس الأي ينص على: "هل يمكن تحديد حجم الاسهام النسبي للمرونة المعرفية المتمثلة في (البدائل المعرفية- الرقابة أو الضبط) في أساليب اتخاذ القرار

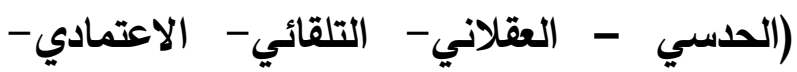
التجنبي) لاى طلبة الدراسات العليا بجامعة أم

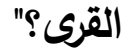
للإجابة على هذا التساؤل تم استخدام تحليل الانحدار Stepwise Regression المتعدد الخطوات Analysis

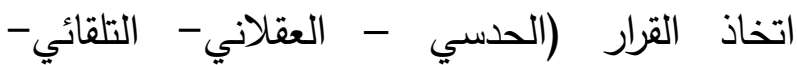

يتضح من الجدول السابق ما يلي: وجود فروق ذات دلالة احصائية في متوسطات درجات البدائل المعرفية لدى طلبة الدراسات العليا بجامعة أم القرى بمكة المكرمة تعزى للعمل الإداري،

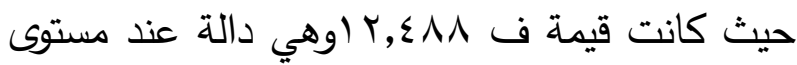
I.,.•، وكانت الفروق لصالح من يمارسون العمل الاداري. كما وجدت فروق ذات دلالة احصائية في متوسطات درجات الرقابة أو الضبط لدى عينة البحث تعزى للعمل الإداري، حيث كانت قيمة ف .0, 0. وهي دالة عند مستوى 0 .,.•، وكانت الفروق لصالح من يمارسون العمل الاداري. ولم توجد عدم فروق ذات دلالة احصائية في متوسطات درجات أبعاد مقياس المرونة المعرفية بين 
الاعتمادي- التجنبي)، وقد تم الحصول علي نمـاذج

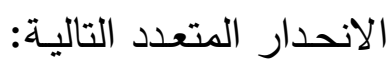

جدول ه اتحليل الانحدار المتعدد للمرونة المعرفية المتمثلة في (البدائل المعرفية- الرقابة أو الضبط) في أساليب اتخاذ القرار (الحسسي - العقلاني- التلقائي- الاعتمادي- التجنبي) لاى طلبة الدراسات العليا بجامعة أم القرى

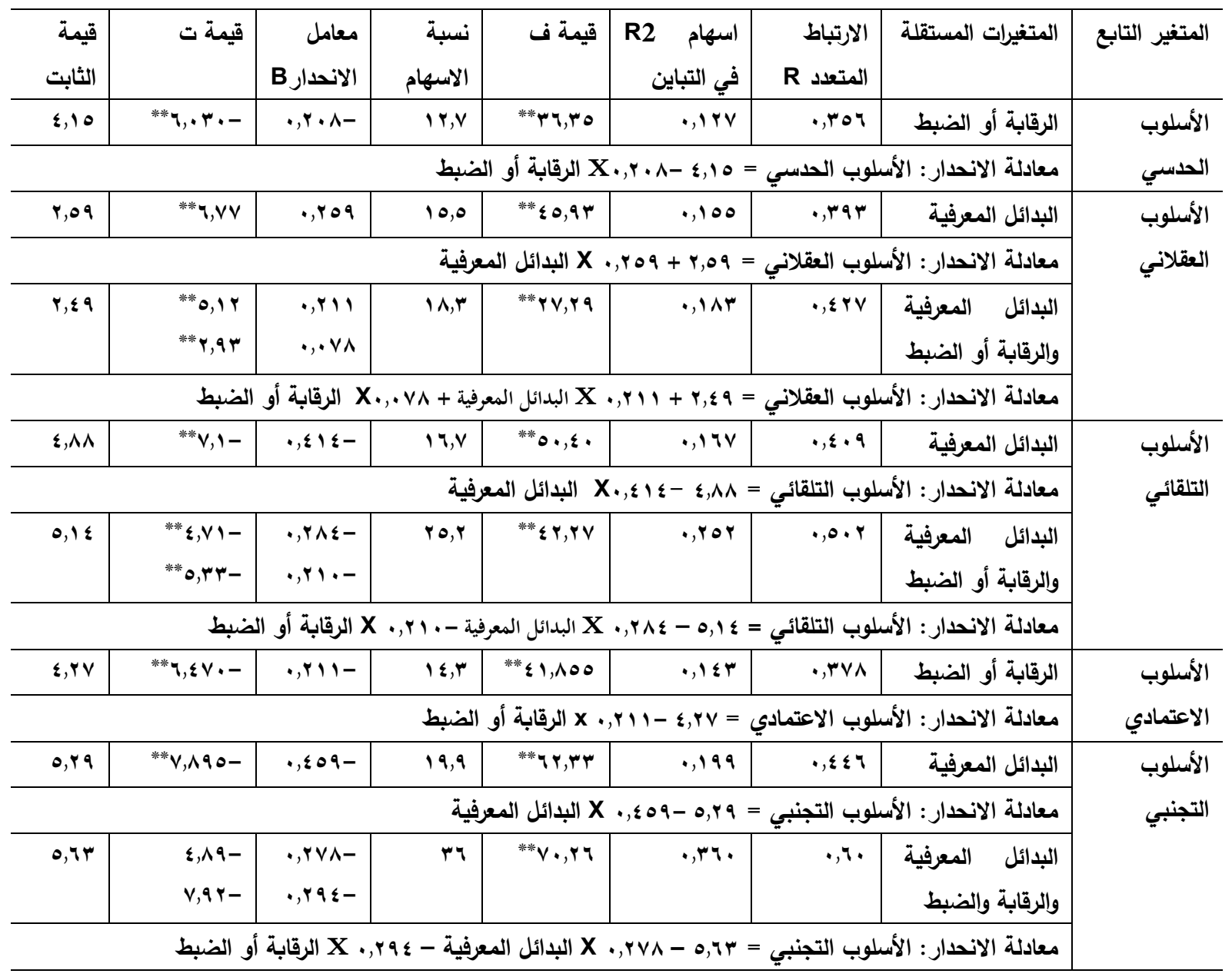

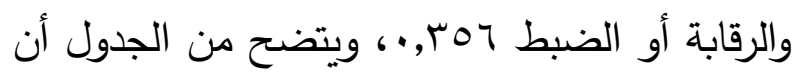
يتضح من الجدول السابق ما يلي:

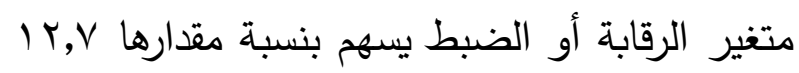
- بالنسبة للأسلوب الحسبي يتضح وجود نموذج \% من التباين في الأسلوب الحدسي. ومن ثم يمكن انحدار متعدد لمتغير الرقابة أو الضبط له تأثير دال

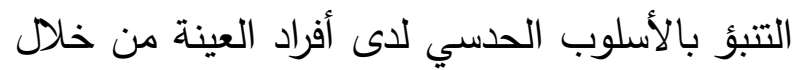
احصائيا على الاسلوب الحدسي، حيث كانت قيمة معرفة درجاتهم على مقياس الرقابة أو الضبط.

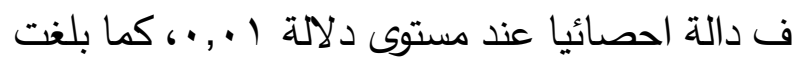
قيمة معامل الارتباط المتعدد بين الأسلوب الحدسي 


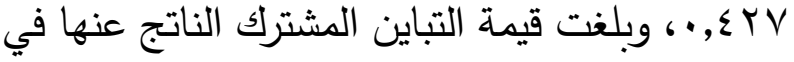

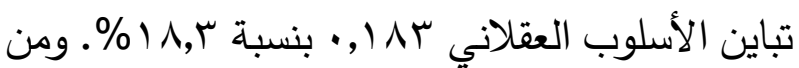
الماحظ أن إضافة متغير الرقابة أو الضبط قد أحدث زيادة في قيمة التباين المشترك مقدارها م ب ., . حيث بلغت قيمة ف لهذا الاسهام rV,rq وهي قيمة دالة احصائيا عند مستوى دلالة ا +.,.، وتقدر نسبة اسهام الرقابة أو الضبط في الأسلوب العقلاني ^, ب \% ، وهذا يؤكد على أهمية الرقابة أو الضبط في التتبؤ بالأسلوب العقلاني لاى عينة البحث. ومن ثم يمكن التنبؤ بدرجات أفراد العينة في متغير الأسلوب العقلاني من خلال معرفة درجاتهم في البدائل المعرفية والرقابة أو الضبط في ضوء أوزان الانحدار والمقدار الثابت لكلا منهما. وعلى ذلك يمكن صياغة المعادلة الانحدارية الدالة على التنبؤ في صورتها النهائية على النحو التالي: الأسلوب العقلاني =

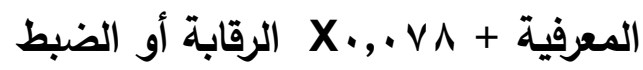
- بالنسبة للأسلوب التلقائي يتضح من النتائج وجود نموذجين انحدار متعدد لمتغيري البدائل المعرفية والرقابة أو الضبط، حيث لهما تأثير دال احصائيا على الأسلوب التلقائي، فقد كانت جميع قيم ف دالة احصائيا عند مستوى دلالة ا +, •، وقد أظهرت نتائج النموذج الأول أن متغير البدائل المعرفية هو أعلى المتغيرات المستقلة ارتباطا بمتغير الأسلوب التلقائي والأكثر اسهاما فيه، حيث بلغت قيمة معامل الارتباط المتعدد بينهما 9 • ع, •، ويسهم متغير البدائل المعرفية
وعلى ذلك يمكن صياغة المعادلة الانحداربة على النحو التالي:

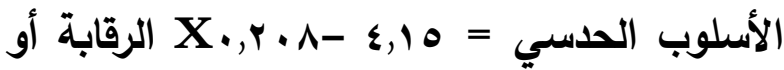
الضبط - بالنسبة للأسلوب العقلاني يتضح وجود نموذجين انحدار متعدد لمتغيري البدائل المعرفية والرقابة أو بودئ الضبط، حيث لهما تأثيرا دال احصائيا على الأسلوب العقلاني، فقد كانت جميع قيم ف دالة احصائيا عند مستوى دلالة ا •, •، وقد أظهرت نتائج النموذج الأول أن متغير البدائل المعرفية هو أعلى المتغيرات المستقلة ارتباطا بمتغير الأسلوب العقلاني والأكثر اسهاما فيه، حيث بلغت قيمة معامل الارتباط المتعدد بينهما سوس,، ، ويسهم متغير البدائل المعرفية بنسبة تباين مقدارها 0,0 \% من تباين متغير الأسلوب العقلاني، ومن ثم يمكن التتبؤ بالأسلوب العقلاني لدى أفراد العينة من خلال معرفة درجاتهم على مقياس

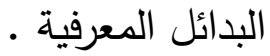
وعلى ذلك يمكن صياغة المعادلة الانحدارية على النحو التالي: الأسلوب العقلاني = المعرفية كما أوضحت نتائج النموذج الثاني أن متغير الرقابة أو الضبط هو المتغير المستقل الثاني في الترتيب والأهمية بالنسبة للأسلوب العقلاني، حيث بلغت قيمة معامل الارتباط المتعدد بين البدائل المعرفية والرقابة أو الضبط وبين الأسلوب العقلاني 
وعلى ذلك يمكن صياغة المعادلة الانحارية الدالة على التنبؤ في صورتها النهائية على النحو التالي:

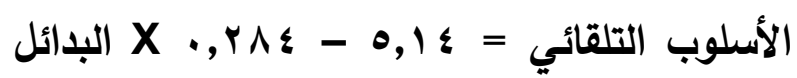

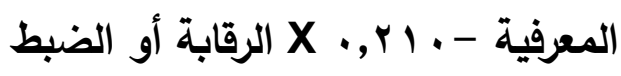
- بالنسبة للأسلوب الاعتمادي يتضح من النتائج

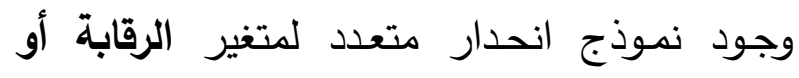

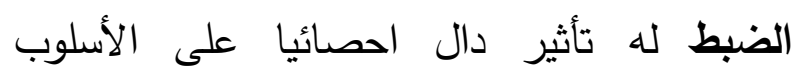
الاعتمادي حيث كانت قيمة ف دالة احصائيا عند مستوى دلالة ا .,..، كما بلغت قيمة معامل الارتباط

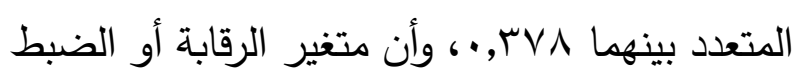

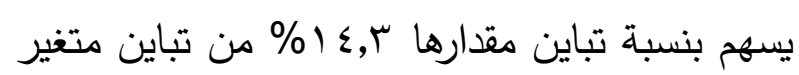

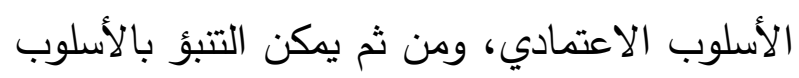
الاعتمادي لدى أفراد العينة من خلال معرفة درجاتهم على مقياس الرقابة أو الضبط. وعلى ذلك يمكن صياغة المعادلة الانحارية على لى الى الى النحو التالي: الأسلوب الاعتمادي = Y Y, أو الضبط الاسطو - بالنسبة للأسلوب التجنبي يتضح من النتائج وجود نموذجين انحدار متعدد لمتغيري البدائل المعرفية

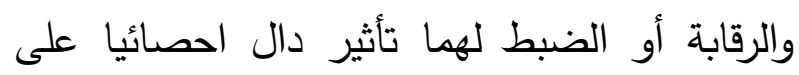

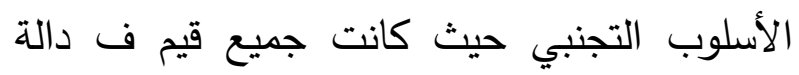
احصائيا عند مستوى دلالة ال,.,، وقد أظهرت نتائج

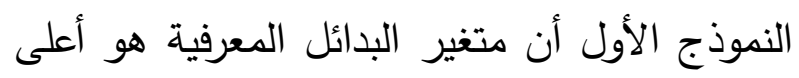

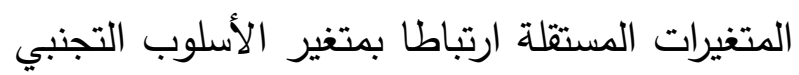

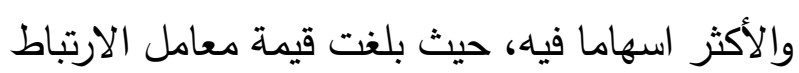

بنسبة تباين مقدارها Y, > ٪\% من تباين متغير الأسلوب التلقائي، ومن ثم يمكن التتبؤ بالأسلوب منارئ

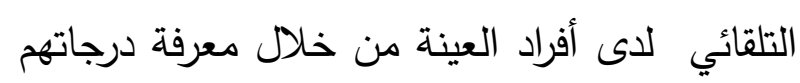
على مقياس البدائل المعرفية. وعلى ذلك يمكن صياغة المعادلة الانحدارية على لى لئل النحو التالي:

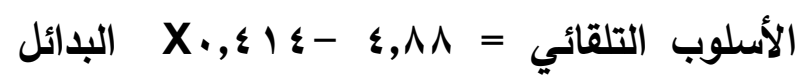
المعرفية كما أوضحت نتائج النموذج الثاني أن متغير الرقابة أو الضبط هو المتغير المستقل الثاني في

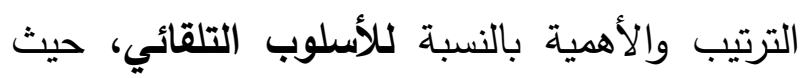
بلغت قيمة معامل الارتباط المتعدد بين البدائل

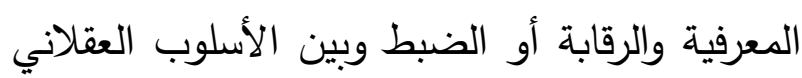

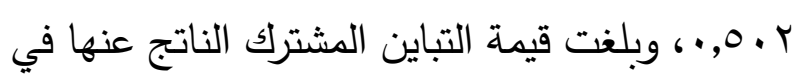

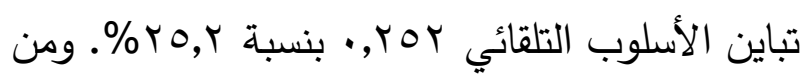
الملاحظ أن إضافة متغير الرقابة أو الضبط قد أحدث

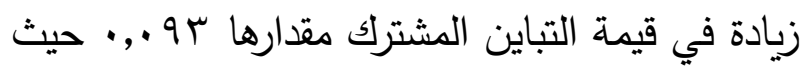

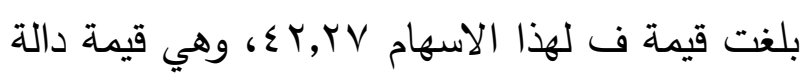

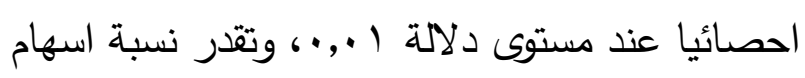

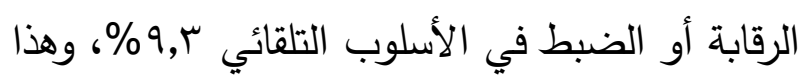

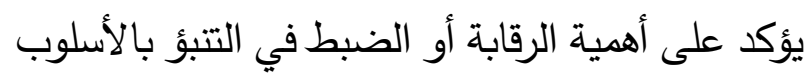
التلقائي لدى عينة البحث. ومن ثم يمكن التنبؤ بدرجات أفراد العينة في متغير الأسلوب التلقائي من

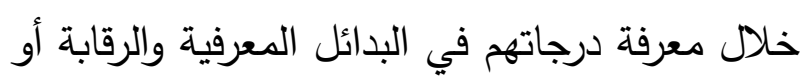
الضبط في ضوء أوزان الانحدار والمقدار الثابت لكلا منهما. 
الضبط، وذلك في ضوء أوزان الانحدار والمقدار الثابت لكلا منهما.

وعلى ذلك يمكن صياغة المعادلة الانحدارية الادالة على التنبؤ في صورتها النهائية على النحو التالي:

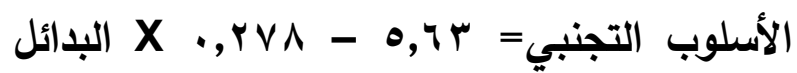

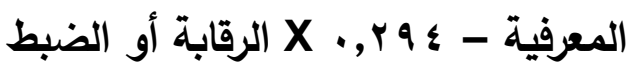

مناقشة النتائج

توصلت نتائج السؤال الأول إلى أن الأسلوب العقلاني قد جاء في الترتيب الأول لأساليب اتخاذ الاذ الان القرار الأكثر استخداما لدى الذكور والإناث والعينة ككل، ثم يليه الأسلوب الاعتمادي، ثم يأتي في المرتبة

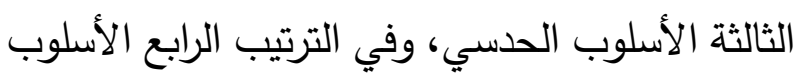

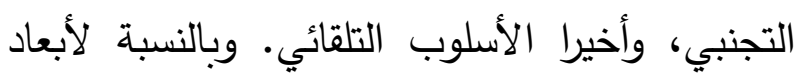
المرونة المعرفية الأكثر استخداما لدى عينة البحث من الذكور والإناث والعينة ككل وكذلك لعينتي طلبة الماجستير والدكتوراة، فقد جاءت البدائل المعرفية في الترتيب الأول، ثم الرقابة أو الضبط. وبالنسبة لطلبة الماجستير فقد اختلفوا عن طلبة الدكتوراه في الترتيب لأساليب اتخاذ القرار من حيث الاستخدام، حيث جاء

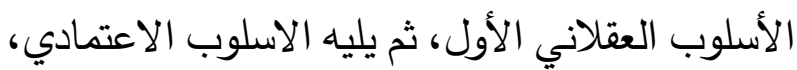

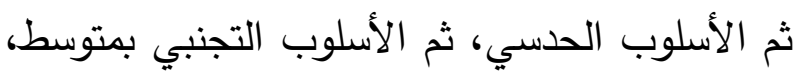

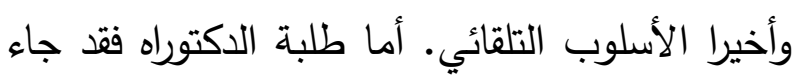

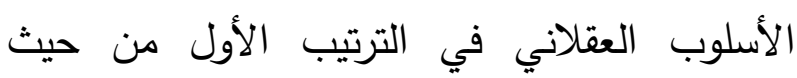
الاستخدام، ثم يليه الاسلوب الحدسي، وفي الترتيب

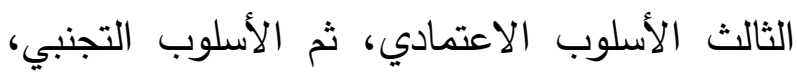
وأخيرا الأسلوب التلقائي، وقد يعود ذلك لأن طلبة الأنادية
المتعدد بينهما 7؟ §, •، وأن متغير البدائل المعرفية يسهح بنسبة تباين مقدارها 9,9 \% من تباين متغير

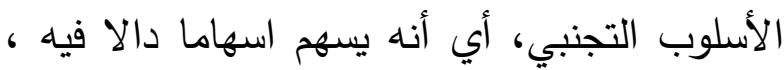
ومن ثم يمكن التتبؤ بالأسلوب التجنبي لإى أفراد العينة من خلال معرفة درجاتهم على مقياس البدائل

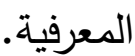
وعلى ذلك يمكن صياغة المعادلة الانحدارية على

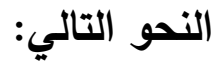

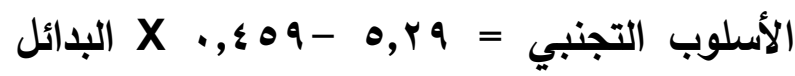

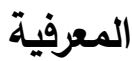

كما أوضحت نتائج النموذج الثاني أن متغير الرقابة أو الضبط هو المتغير المستقل الثاني في

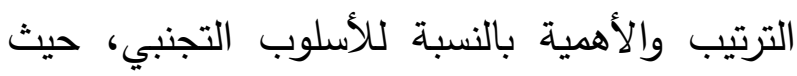
بلغت قيمة معامل الارتباط المتعدد بين البدائل المعرفية والرقابة أو الضبط وبين الأسلوب العقلاني

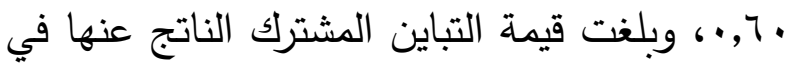

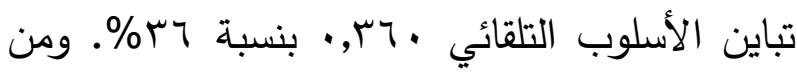
الملاحظ أن إضافة متغير الرقابة أو الضبط قد أحدث

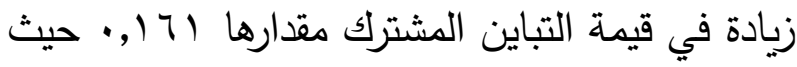
بلغت قيمة ف لهذا الاسهام \ب, •لوهي قيمة دالة احصائيا عند مستوى دلالة ا.,..، وتقدر نسبة اسهام الرقابة أو الضبط في الأسلوب التجنبي ا,7 (1\%، وهذا

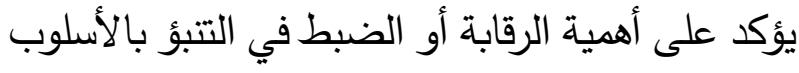
التجنبي لدى عينة البحث. ومن ثم يمكن التتبؤ

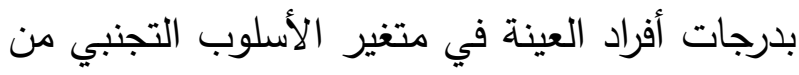
خلال معرفة درجاتهم في البدائل المعرفية والرقابة أو لوني 
المنطقي لها مما يتماشى مع المرونة المعرفية حيث توصف بأنها القدرة على التبديل بين أنواع المعالجة (Diamond, 2013) والضبط والتحكم بالموقف المدرك. وبهذا المعنى تكون العلاقة بينها وبين بقية الأساليب وهي الاعتمادي والحدسي والتجنبي والتلقائي سالبة لأنها أساليب تقتقد المرونة في عملية اتخاذ القرار كما توصلت نتائج السؤال الثالث إلى وجود فروق ذات دلالة احصائية في متوسطات درجات الأسلوب التلقائي والأسلوب التجنبي لدى طلبة الدراسات العليا بجامعة أم القرى بمكة المكرمة تعزى الاسول للعمل الإداري لصالح من لا يمارسون العمل الإداري، وقد يعود ذلك لأن العمل الإداري يستجوب الحذر مرإ والتدقيق ويكسب الفرد الحرص في المواقف المختلفة، فيقل لديهم استخدام الأسلوب التلقائي والأسلوب التجنبي عكس من لا يمارسون العمل الإداري. كما وجدت فروق ذات دلالة احصائية في متوسطات درجات الأسلوب الحدسي والعقلاني بين الذكور والإناث من طلبة الدراسات العليا بجامعة أم القرى، وكانت الفروق لصالح الإناث. وقد يعود ذلك للضغوط والجهد الضخم المطلوب خلال مرحلة الدراسات العليا، فتميل النساء خلال هذه الاحداث المجهدة إلى اتخاذ القرارات بصورة أفضل من الرجال وأكثر فائدة، كما انهن أكثر وعيا وادراكا تحت هذه الظروف وهذا ما توصل له العديد من علماء الاعصاب كالدكتورة ستيفاني بريستون Stephanie D. Preston عام V . . . ، حيث وجدت أنه عندما تخضع المرأة لرد
الدكتوراة عندما يستخدمون الأسلوب الحدسي الذي يتصف بالتدقيق بالمعلومات والاعتماد على المشاعر والهواجس في اتخاذ القرار قبل اللجوء للأسلوب الاعتمادي والذي يعتمد على النصيحة والإرشاد من الآخرين قبل القيام باتخاذ القرار فإنهم يعتمدون على نضجهم وخبرتهم بالتعامل مع الاحداث، حيث تعتبر نقص الخبرة والمعرفة ومحدوديتها بالمجال من العوامل المؤثرة بعملية اتخاذ القرار (الريماوي، ج +. . ب)، مما يجعلهم يميلون للاعتماد على انفسهم أكثر من طلبة الماجستير في اتخاذ القرارات عند يواجهون موقف غير واضتح المعالم.

وتوصلت نتائج السؤال الثاني أن هناك علاقة ارتباطية بين أساليب اتخاذ القرار (العقلانيالتلقائي - التجنبي) وبين البدائل المعرفية، ولكنها كانت سالبة بالنسبة للأسلوب (التلقائي - التجنبي)، وموجبة بين الأسلوب العقلاني والبدائل المعرفية. كما أن هناك علاقة ارتباطية بين أساليب اتخاذ القرار (الحدسي العقلاني - التلقائي - الاعتمادي - التجنبي) والرقابة أو الضبط، وكانت هذه العلاقة موجبة بين الرقابة أو الضبط والأسلوب العقلاني، وسالبة بالنسبة لباقي الأساليب وذلك لعينة الذكور • بالنسبة لعينة الإناث والعينة الكلية فقد كانت علاقة سالبة بين جميع أساليب اتخاذ القرار وابعاد المرونة المعرفية، ما عدا الأسلوب العقلاني فقد كانت العلاقة موجبة. وهذا قد يعود لخصائص الأسلوب العقلاني الذي يوصف بالبحث الشامل عن المعلومات وضع قائمة بالبدائل والتقييم 


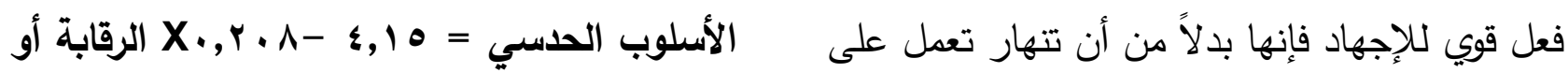

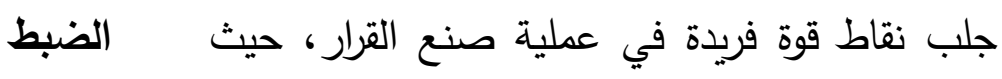

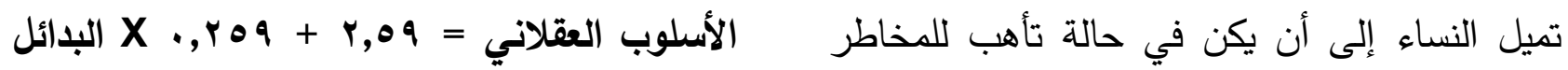
تحت الضغط ويتجهن نحو البحث عن النجاحات المعرفية

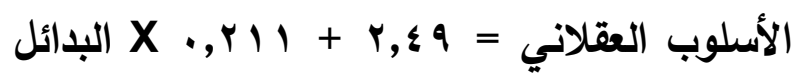
الصغيرة والمقننة (Caprine,2016). كما أنه لا توجد

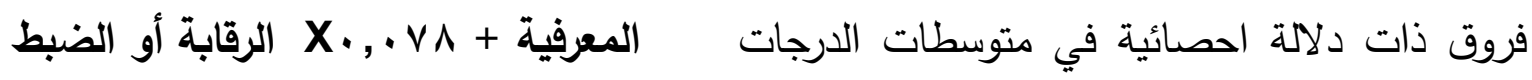
الكلية لأبعاد مقياس أساليب اتخاذ القرار (الحدسي المعرفية الأسلوب التلقائي =

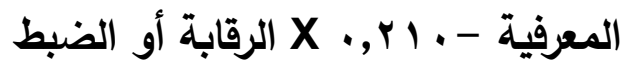

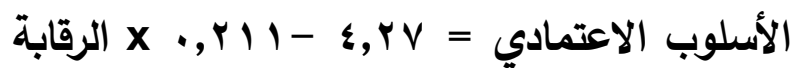
أو الضبط

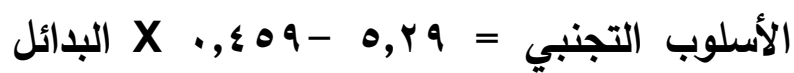
المعرفية

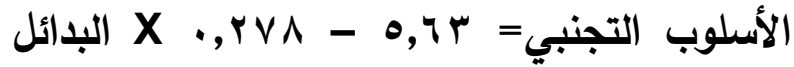

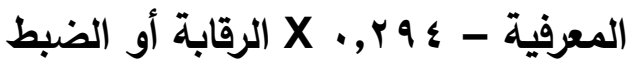
وهذه النتيجة تؤكد أهمية المرونة بالمرونة النسبة

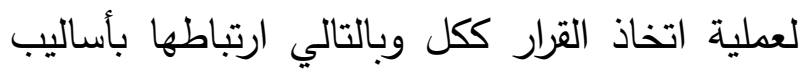
اتخاذ القرار للى الافراد، والذي أكدته نتائج هذا البحث. حيث تعتبر المرونة المعرفية هي قدرة صناع القرار على مطابقة نوع المعرفة مع معالجة نوع المشكلة التي تواجههم، وكيفية استخدامهم المرونة المعرفية لمطابقة المعالجة المعرفية للمشكلة واتخاذ القرار (Laureiro-Martínez \& Brusoni,2017). المراجع

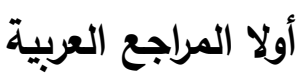

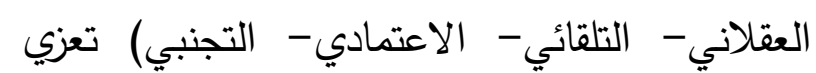
للتفاعل بين العمل الإداري والنوع. كما توصلت نتائج السؤال الرابع إلى وجود فروق ذات دلالة احصائية في متوسطات درجات البدائل المعرفية والرقابة أو الضبط لدى طلبة الدراسات

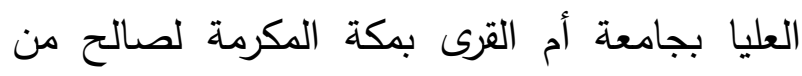
يمارسون العمل الاداري. وقد يعود ذلك لأن من النها يمارسون العمل الإداري يتعاملون مع العديد من الموظفين وطالبي الخدمة فيحتاجون للتمتع بمرونة أكبر من غير الممارسين لتسيير الاعمال وحل المشكلات والرفع من إنتاجية العمل. كذلك لا توجد فروق ذات دلالة احصائية في متوسطات درجات أبعاد مقياس المرونة المعرفية بين الذكور والإناث من طلبة الدراسات العليا تعزى للتفاعل بين النوع والعمل الإداري، وهذا يؤكد ان المرونة بالعمل الإداري لا تتأثر

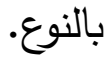
كذلك توصلت نتائج السؤال الخامس إلى أن هناك إمكانية تحديد حجم الاسهام النسبي للمرونة المعرفية في أساليب اتخاذ القرار على النحو التالي: 


$$
\text { سميرة محارب العتيبي }
$$

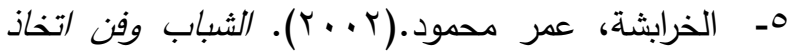

$$
\begin{aligned}
& \text { القرار، مطابع الدستور التجارية، عمان. }
\end{aligned}
$$

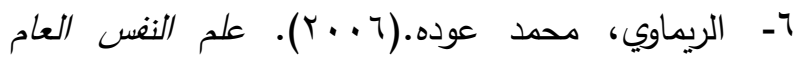

$$
\begin{aligned}
& \text { (الطبعة الثانية)، عمان، دار المسيرة للنشر والتوزيع. }
\end{aligned}
$$

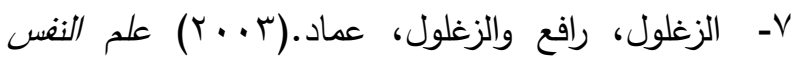

$$
\begin{aligned}
& \text { المعرفي، عمان، دار الشرق للنشر والتوزيع، الطبعة الأولى. }
\end{aligned}
$$

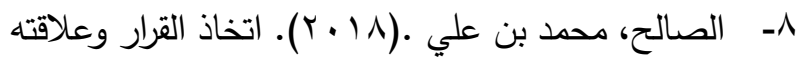

$$
\begin{aligned}
& \text { بالمرونة النفسية لاى رؤساء الأقسام الأكاديمية في جامعة الحة }
\end{aligned}
$$

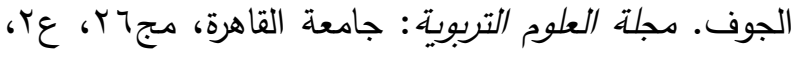

$$
\begin{aligned}
& .17-r . \varepsilon \\
& \text { 9- الفرماوي، حمدي.(ع 99 ()). الأساليب المعرفية بين } \\
& \text { النظرية والبحث، القاهرة، مكتبة الانجلو المصرية. }
\end{aligned}
$$

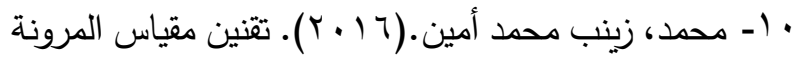

$$
\begin{aligned}
& \text { العقلية لاى طلاب الجامعة. مجلة العلوم التربوية: جامعة }
\end{aligned}
$$

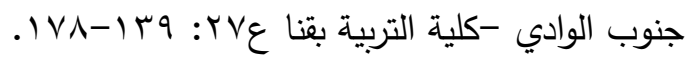

\section{ثانيا المراجع الانجليزية}

11- Anderson J. A. (2000). Intuition in manager; Are intuitive managers more effective? journal of Managerial. 15(1):46-63 . 12- Anderson, P. (2002). "Assessment and development of executive function (EF) during childhood". Child Neurophysiology. Vol. 8. No. 2. PP. 71-83.

13- Bekel, A. \& Ulubey, E. (2015). the role of cognitive flexibility on explanation adolescents coping strategies, Electronic Journal of social sciences, 14(55),291-302.

14- Betsch, T., Haberstroh, S., Glöckner, A., Haar, T., \& Fiedler, K. (2001). The effects of routine strength on adaptation and information search in recurrent decision making. Organizational Behavior and Human Decision Processes, 84(1), 23-53.

15- Cañas, J. (2006) Cognitive Flexibility.In book: International encyclopedia of

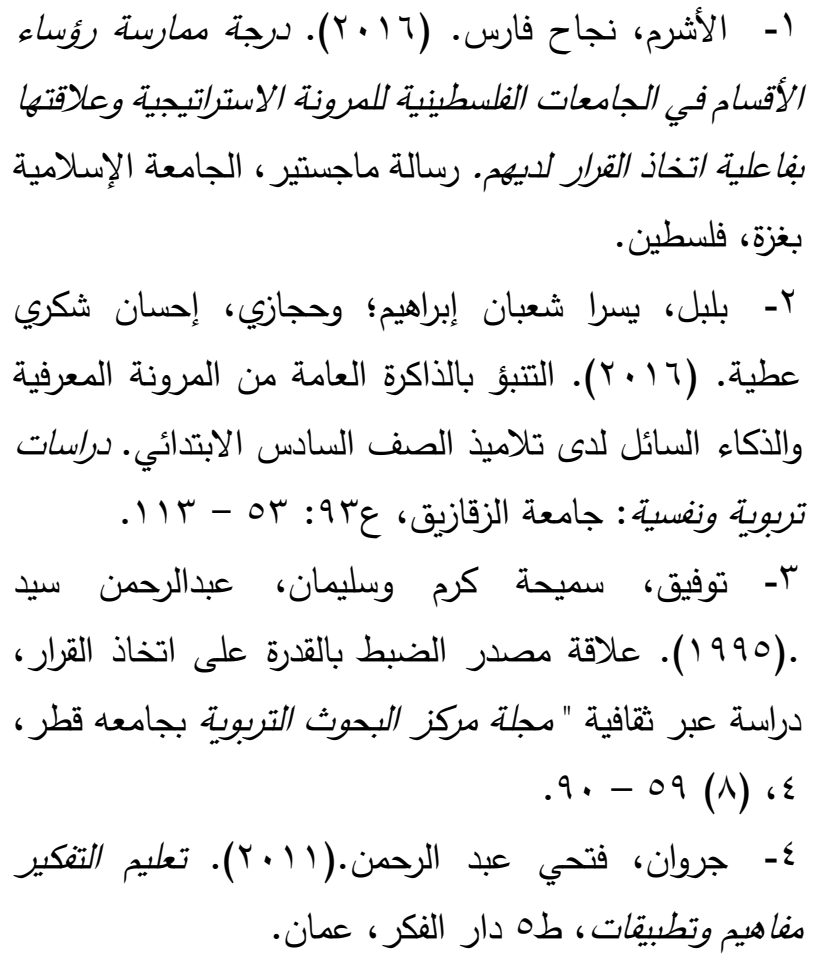

ergonomics and human factors, Editors: Waldemar Karwowski, pp.297-300.

16- Caprine, K. (2016). How DecisionMaking Is Different Between Men and Women and Why It Matters In Business, https://www.forbes.com/sites/kathycaprino/20 16/05/12/how-decision-making-is-differentbetween-men-and-women-and-why-it-mattersin-business/\#2788cef34dcd

17- Coscarelli, W. C. \& Johnson, D. (2007). Decison-Making Style Inventory, Participant's Workbook, Pfeiffer; 1 edition, ISBN10: 0787988413

18- Davids, E. L., Roman, N. V., \& Leach, L. (2016). Decision-making styles: A systematic review of their associations with parenting. Adolescent Research Review, 1(1), 69-90.

19- Dennis, J. \& Vander, W. (2010) . "The cognitive flexibility inventory: instrument development and estimates of reliability and validity ". Cognitive therapy research.Vol. 34. No. 3. PP. 253-341. 
20- Diamond, A. (2013). Executive functions. Annual Review of Psychology, 64, 135-168.

21- Driver, M. J., Brousseau, K. E., \& Hunsaker, P. L. (1993). The dynamic decision maker. San Francisco: Jossey-Bass Publishers. 22- Driscoll, M. (2000) Psychology of Learning for Instruction. http://ocw.metu.edu.tr/pluginfile.php/9013/mo d_resource/content/1/driscoll-ch10\%20(1).pdf 23- Foldy, E. G., Goldman, L., \& Ospina, S. (2008). Sensegiving and the role of cognitive shifts in the work of leadership. The Leadership Quarterly, 19(5), 514-529.

24- Furnham, A. (2005). the psychology of behavior at work; The individual in the organization, Psychology press, $2^{\text {nd }}$ ed.

25- Furr, N. R., Cavarretta, F., \& Garg, S. (2012). Who changes course? The role of domain knowledge and novel framing in making technology changes. Strategic Entrepreneurship Journal, 6(3), 236-256.

26- Geisler, M., \& Allwood, C. M. (2017). Relating decision-making styles to social orientation and time approach. Journal of Behavioral Decision-Making .

https://onlinelibrary.wiley.com/doi/full/10.100 2/bdm.2066

27- Grégoire, D. A., Barr, P. S., \& Shepherd, D. A. (2010). Cognitive processes of opportunity recognition: The role of structural alignment. Organization Science, 21(2), 41343.

28- Gunduz, B. (2013). Emotional intelligence, cognitive flexibility and psychological symptoms in pre-service teachers. Educational Research and Reviews, 5(13), pp. 1048-1056.

29- Jacoby, J. M., (2007). Relationship between Principals' Decision-Making Styles and Technology Acceptance \& Use, University of Pittsburgh- Electronic Thesis and Dissertation Archive, http://etd.library.pitt.edu/ETD/available/etd01022007-223237
30- Laureiro-Martínez D, Brusoni S. (2018).Cognitive flexibility and adaptive decision-making: Evidence from a laboratory study of expert decision makers. Strat Mgmt J. 39:1031-1058.

https://doi.org/10.1002/smj.2774

31- Laureiro-Martínez, D. L.; Bruson, S. \& Zollo, M. (2009). Cognitive Flexibility in Decision-Making: A Neurological Model of Learning and Change. CROMA - Center for Research in Organization and Management Bocconi University. CROMA Working paper 09-014.

32- Leykin, Y., \& DeRubeis, R. J. (2010). Decision-making styles and depressive symptomatology: Development of the Decision Styles Questionnaire. Judgment and DecisionMaking, 5(7), 506-515.

33- Nadkarni, S., \& Narayanan, V. K. (2007). Strategic schemas, strategic flexibility, and firm performance: The moderating role of industry clockspeed. Strategic Management Journal, 28(3), 243-270.

34- Pachur, T., \& Spaar, M. (2015). Domainspecifc preferences for intuition and deliberation in decisionmaking. Journal of Applied Research in Memory and Cognition, 4(3), 303-311.

35- Payne, J. W., Bettman, J. R., \& Johnson, E. J. (1988). Adaptive strategy selection in decision making. Journal of Experimental Psychology: Learning, Memory, and Cognition, 14(3), 534.

36- Raes, A. M., Heijltjes, M. G., Glunk, U., \& Roe, R. A. (2011). The interface of the top management team and middle managers: A process model. Academy of Management Review, 36(1), 102-126.

37- Rowe, A. J., \& Boulgarides, J. D. (1983). Decision Styles- A perspective. Leadership and Organization Development Journal,12(4), 3-9. 38- Scott, S. G., \& Bruce, R. A. (1995). Decision-making style: the development and assessment of a new measure. Educational and Psychological Measurement, 55(5), 818-831. 
39- Slovic,p.( 1990 ) Chaice . In D, Osheron, \& E., Smith (Eds) An Invitation to cognitive Science. Thinking VOL. 3 london : The MT Press

40- Sternberg, R. J., \& Li-fang Z. (2001). Perspective on thinking, learning and cognitive styles. Mahwah, N.J: Lawrence Erlbaum Associates.
41- Thunholm, P. O. (2004). Decisionmaking style: Habit, style or both? Personality and Individual Differences, 36(4), 931-944. 42- Turpin, SM \& Marais, MA (2004). Decision-making: Theory and practice, ORiON Journal,20(2), pp. 143-160. 


\title{
The size of the relative contribution to cognitive flexibility in decision-making methods among post graduate students at Umm Al-Qura University
}

\author{
Sameera Moharib AL_Otibia \\ Associate Professor of Educational Psychology \\ Department of Psychology - Umm Al-Qura University
}

\begin{abstract}
The current research aims to identify the most common decision-making methods and the most dimensions of flexibility used by post graduate students at Umm Al-Qura University, and to uncover statistically significant differences in the mean overall scores for the dimensions of the scale of the methods of Decisionmaking and the dimensions of cognitive flexibility if the administrative work is present or not, and determining the size of the relative contribution of the dimensions of cognitive flexibility in decisionmaking methods in the study sample consisting of 235 male and female postgraduate students. The measure of decision-making methods and the Cognitive Resilience Scale, the results concluded that the rational method comes first followed by the dependent method, then the intuitive method, then the avoidance method, and finally the automatic method. As for arranging the dimensions of cognitive flexibility, the cognitive alternatives come then control or discipline. Also, statistically significant differences were found in the mean scores of the automatic method, the avoidance method, the cognitive alternatives, and the control or discipline due to administrative work in favor of those who do not practice administrative work, and it was also possible to determine the size of the relative contribution of the dimensions of cognitive flexibility in the methods of decision-making.
\end{abstract}

Key Words: cognitive flexibility, decision-making methods- graduate students -Umm Al-Qura University 